\title{
A multiomics analysis of S100 protein family in breast cancer
}

\author{
Patrizia Cancemi i,2,3, Miriam Buttacavoli ${ }^{1}$, Gianluca Di Cara ${ }^{2}$, Nadia Ninfa Albanese $^{2}$, \\ Serena Bivona ${ }^{3}$, Ida Pucci-Minafra² ${ }^{2}$ and Salvatore Feo I,3,4 $^{1,3}$ \\ ${ }^{1}$ Department of Biological Chemical and Pharmaceutical Sciences and Technologies (STEBICEF), University of Palermo, \\ Palermo, Italy \\ ${ }^{2}$ Center of Experimental Oncobiology (C.OB.S.), La Maddalena Hospital III Level Oncological Dept., Palermo, Italy \\ ${ }^{3}$ Advanced Technologies Network Center (ATeN), University of Palermo, Palermo, Italy \\ ${ }^{4}$ Institute of Biomedicine and Molecular Immunology, CNR, Palermo, Italy \\ Correspondence to: Patrizia Cancemi, email: patrizia.cancemi@unipa.it \\ Keywords: 100 proteins; breast cancer; expression analysis; proteomics; pathway analysis \\ Received: February 05, $2018 \quad$ Accepted: May 19, $2018 \quad$ Published: June 26, 2018 \\ Copyright: Cancemi et al. This is an open-access article distributed under the terms of the Creative Commons Attribution License \\ 3.0 (CC BY 3.0), which permits unrestricted use, distribution, and reproduction in any medium, provided the original author and \\ source are credited.
}

\section{ABSTRACT}

The S100 gene family is the largest subfamily of calcium binding proteins of EFhand type, expressed in tissue and cell-specific manner, acting both as intracellular regulators and extracellular mediators. There is a growing interest in the $\mathbf{S 1 0 0}$ proteins and their relationships with different cancers because of their involvement in a variety of biological events closely related to tumorigenesis and cancer progression. However, the collective role and the possible coordination of this group of proteins, as well as the functional implications of their expression in breast cancer (BC) is still poorly known. We previously reported a large-scale proteomic investigation performed on BC patients for the screening of multiple forms of S100 proteins. Present study was aimed to assess the functional correlation between protein and gene expression patterns and the prognostic values of the $\mathbf{S 1 0 0}$ family members in BC. By using data mining, we showed that $\mathbf{S} 100$ members were collectively deregulated in BC, and their elevated expression levels were correlated with shorter survival and more aggressive phenotypes of BC (basal like, HER2 enriched, ER-negative and high grading). Moreover a multi-omics functional network analysis highlighted the regulatory effects of S100 members on several cellular pathways associated with cancer and cancer progression, expecially immune response and inflammation. Interestingly, for the first time, a pathway analysis was successfully applied on different omics data (transcriptomics and proteomics) revealing a good convergence between pathways affected by S100 in BC. Our data confirm S100 members as a promising panel of biomarkers for BC prognosis.

\section{INTRODUCTION}

Breast cancer is the most diagnosed and potentially aggressive form of cancer in women [1]. Although genetic alterations in proto-oncogenes, tumor suppressor genes, cell cycle regulators and cell growth factors have been implicated in the process of carcinogenesis, the progression toward full malignancy is extremely complex at molecular level [2]. Different protein factors can be over/under expressed simultaneously and activate/ deactivate different cell functions. Breast cancer is a multifaceted disease of distinct biological subtypes with different clinical, pathological, molecular features and proteomic differences [3-9]. The molecular classification of breast cancer, based on the expression of estrogen/ progesterone receptor (ER/PR) and epidermal growth factor receptor 2 (HER2), provides different prognostic/ predictive implications and therapeutic informations. Despite these advances, breast cancer remains one of the most enigmatic and poorly predictable cancer in its 
evolution due to the elevated biological heterogeneity consistent with observed varied responses to therapies across patients [6]. Thus novel biomarkers useful in clinical setting and/or for breast cancer management are coming up to explore.

One class of protein with emerging roles in breast cancer is the S100 family, a multigenic family of $\mathrm{Ca}^{2+}$ binding proteins of the EF-hand type, comprising at least 20 members [10]. The majority of them (S100A1-S100A16) are coded by genes that clustered at chromosome locus 1q21 (known as epidermal differentiation complex), while the others (S100B, S100G, $\mathrm{S} 100 \mathrm{P}$ and S100Z) are located in other chromosome loci, 21q22, Xp22, 4p16 and 5q14, respectively [11]. It is well documented that $\mathrm{S} 100$ proteins have a broad range of intracellular and extracellular functions, and are implicated in multiple biological functions, including cell division, motility, secretion, protein synthesis, and membrane permeability [12]. In addition, recent studies have reported the association between S100 family members and breast cancer development and progression [13-15]. Despite the promising potential of the S100 family as a biomarker panel, there are few studies that have addressed the family-wide expression of S100 protein isoforms in clinical samples [16-20]. We recently reported a large proteomic screening for S100 protein expression on breast cancer patients [21]. The results showed that some protein members are ubiquitously expressed in almost all patients, while others appeared more sporadic within the same group, and most of the detected S100 members appeared reciprocally correlated. More interestingly, patients which developed distant metastases showed a general tendency of higher S100 protein expression, compared to the disease-free group.

However, the mode of action of S100 proteins in breast cancer as well as the functional implications of alteration of gene expression levels remain to be elucidated.

Here, we performed a deep in silico analysis on the transcriptional profiles of $20 \mathrm{~S} 100$ family members (S100A1-S100A16, S100B, S100G, S100P and S100Z) between cancer and normal tissues. Moreover, S100 gene expression levels were correlated to the clinicpathological features (Molecular subtypes, ER status, Grading) and survival data, evaluated as Overall Survival (OS), Distant Metastasis Free Survival (DMFS), and Relapse Free Survival (RFS). Finally, by using three cross platforms (GOBO, ONCOMINE and STRING databases) and our previous proteomic data, we explored the S100-regulated networks and pathways. Our results revealed that S100 genes were de-regulated in BC patients compared with normal tissues and collectively were over-expressed in HER2 enriched and Basal-like subtypes. In survival analysis, high transcriptional levels of S100 genes were associated with worse prognosis, probably because S100 expression affects immune response and inflammatory pathways. This study represents the first multi-omics attempt capable of revealing an integrated view of biological mechanisms regulated by $\mathrm{S} 100$ protein family and meaningful the important involvement of S100 family in breast cancer progression.
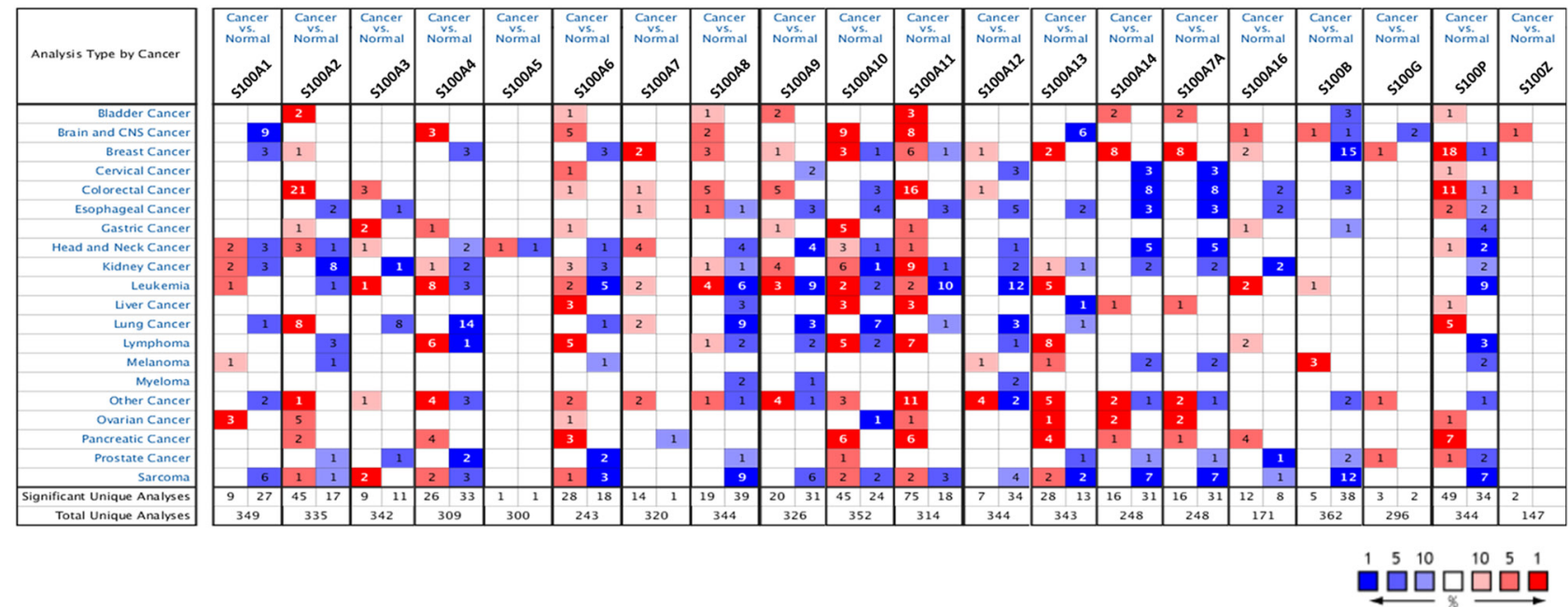

Figure 1: Gene expression analysis of S100 family members between normal and cancer tissues. The mRNA expression differences between tumors and normal tissues were analyzed for each S100 gene in ONCOMINE database using the following thresholds: p-value: 1E-4; fold change: 2; gene rank: top 10\%; data type: mRNA; sample type: clinical specimens. The number in the colored box represents the number of analyses meeting these thresholds. The color depth was determined by the gene rank. The red boxes indicate that the mRNA levels of target genes are higher in tumor tissues than in normal tissues, while blue boxes indicate that the mRNA levels of target genes are lower in tumor tissues than in normal tissues. 


\section{RESULTS}

\section{Gene expression analysis of S100 family members between normal and cancer tissues}

The transcription levels of the S100 family members between tumor and normal tissues in multiple cancers was compared by using ONCOMINE database [22]. As shown in Figure 1, the database performed a total of 6037 unique analyses for all the S100 genes across a wide variety of datasets in different cancer types and 840 showed a significant statistical difference for mRNA expression. In particular, S100 family members were found upregulated in 429 analyses, and down-regulated in 411 cancer versus normal analyses. These results suggest that S100 family members might play important roles during carcinogenesis in different cancer types, acting both as oncogenes or suppressor genes. In particular, for breast cancer, ONCOMINE analysis revealed that collectively S100 mRNA expression was higher in tumoral than

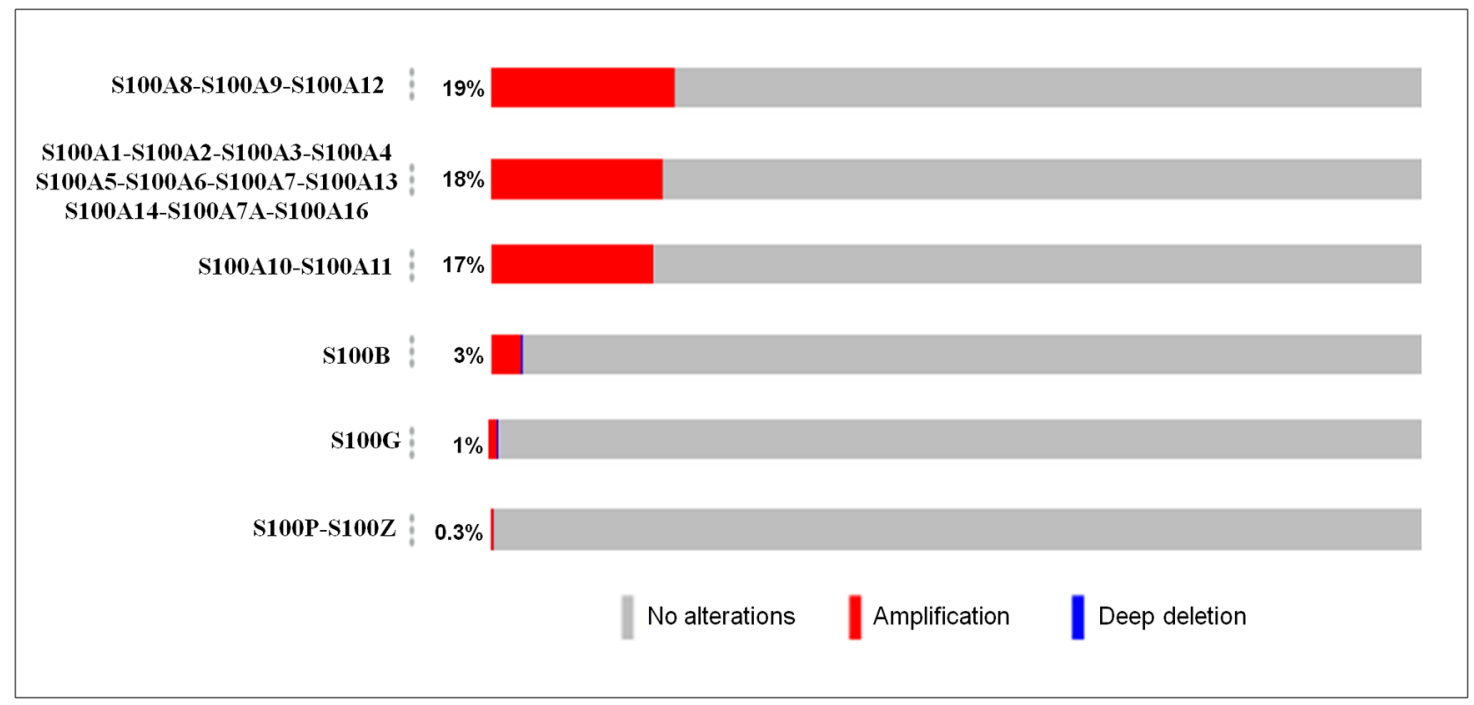

Figure 2: Genetic alterations of S100 genes in breast cancer. The percentage of alterations in S100 genes was extracted by using the OncoPrint tool of cBioportal containing sequencing data of 2509 patients. Red and blue represent amplification and deep deletion, respectively.

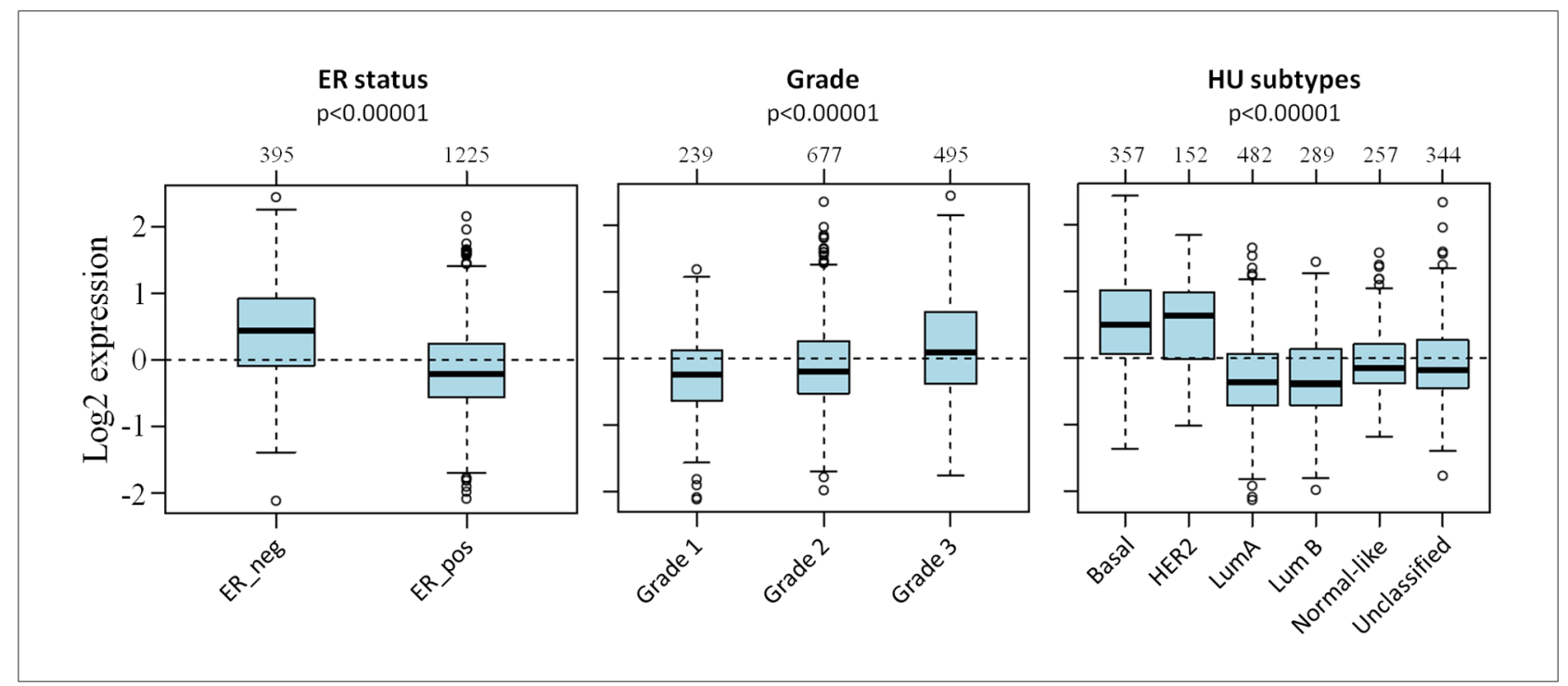

Figure 3: Association between S100s gene expression and clinical parameters. Box Plot of the mRNA expression of S100 family members. Patients were stratified according ER status, tumor grading and HU subtypes applying the gene Set Analysis (GSA) of GOBO database. 
Table 1: Correlation of S100s with survival outcomes in breast cancer patients

\begin{tabular}{|c|c|c|c|c|c|c|c|}
\hline Gene ID & Affimetrix ID & $\begin{array}{l}\text { Survival } \\
\text { outcome }\end{array}$ & $\begin{array}{c}\text { Number of } \\
\text { cases }\end{array}$ & Cut-off & $\begin{array}{l}\text { Expression range } \\
\text { of the probe }\end{array}$ & HR & LogrankP \\
\hline \multirow[t]{3}{*}{ S100A1 } & 205334-at & RFS & 3955 & 262 & $4-14584$ & 0.87 & 0.016 \\
\hline & & DMFS & 1746 & 274 & $4-14584$ & 0.92 & 0.38 \\
\hline & & OS & 1402 & 233 & $4-10656$ & 0.74 & 0.006 \\
\hline \multirow[t]{3}{*}{ S100A2 } & 204268-at & RFS & 3955 & 269 & $3-72629$ & 0.95 & 0.31 \\
\hline & & DMFS & 1746 & 284 & $7-33668$ & 0.97 & 0.74 \\
\hline & & OS & 1402 & 308 & $6-72629$ & 0.98 & 0.85 \\
\hline \multirow[t]{3}{*}{ S100A3 } & 206027-at & RFS & 3955 & 68 & $3-7734$ & 0.94 & 0.26 \\
\hline & & DMFS & 1746 & 68 & 4-1799 & 1.07 & 0.48 \\
\hline & & OS & 1402 & 80 & $3-1799$ & 0.95 & 0.64 \\
\hline \multirow[t]{3}{*}{ S100A4 } & 203186-s-at & RFS & 3955 & 2626 & $37-33152$ & 1.12 & 0.044 \\
\hline & & DMFS & 1746 & 2597 & $122-27019$ & 1.1 & 0.33 \\
\hline & & OS & 1402 & 2840 & $122-27019$ & 0.97 & 0.77 \\
\hline \multirow[t]{3}{*}{ S100A5 } & 207763-at & RFS & 3955 & 14 & $1-314$ & 0.87 & 0.012 \\
\hline & & DMFS & 1746 & 14 & $2-314$ & 0.97 & 0.76 \\
\hline & & OS & 1402 & 16 & $2-291$ & 1 & 0.98 \\
\hline \multirow[t]{3}{*}{ S100A6 } & 217728-at & RFS & 3955 & 5323 & $418-52048$ & 1.07 & 0.2 \\
\hline & & DMFS & 1746 & 5293 & $739-49544$ & 1.02 & 0.81 \\
\hline & & OS & 1402 & 5824 & $419-50535$ & 0.81 & 0.049 \\
\hline \multirow[t]{3}{*}{ S100A7 } & 205916-at & RFS & 3955 & 39 & $1-55811$ & 1.17 & 0.0038 \\
\hline & & DMFS & 1746 & 46 & $2-52684$ & 1.26 & 0.0019 \\
\hline & & OS & 1402 & 79 & $2-55811$ & 1.23 & 0.062 \\
\hline \multirow[t]{3}{*}{ S100A8 } & 202917-s-at & RFS & 3955 & 514 & $3-128800$ & 1.45 & $2.60 \mathrm{E}-11$ \\
\hline & & DMFS & 1746 & 545 & $2-55811$ & 1.38 & 0.0012 \\
\hline & & OS & 1402 & 700 & $3-128800$ & 1.4 & 0.0021 \\
\hline \multirow[t]{3}{*}{ S100A9 } & 203535-at & RFS & 3955 & 341 & $5-94557$ & 1.41 & $5.50 \mathrm{E}-10$ \\
\hline & & DMFS & 1746 & 331 & $5-43408$ & 1.41 & 0.00047 \\
\hline & & OS & 1402 & 430 & $13-94557$ & 1.38 & 0.0031 \\
\hline \multirow[t]{3}{*}{ S100A10 } & 200872-at & RFS & 3955 & 6750 & $522-38772$ & 1.35 & $8.00 \mathrm{E}-08$ \\
\hline & & DMFS & 1746 & 6626 & $522-28029$ & 1.43 & 0.00031 \\
\hline & & OS & 1402 & 6383 & $522-38778$ & 1.26 & 0.037 \\
\hline \multirow[t]{3}{*}{ S100A11 } & 200660-at & RFS & 3955 & 8844 & $162-57630$ & 1.45 & $3.10 \mathrm{E}-11$ \\
\hline & & DMFS & 1746 & 8468 & $302-57630$ & 1.41 & 0.00052 \\
\hline & & OS & 1402 & 8844 & $241-33276$ & 1.28 & 0.022 \\
\hline \multirow[t]{3}{*}{ S100A12 } & 205863-at & RFS & 3955 & 83 & $1-3261$ & 0.78 & $1.20 \mathrm{E}-05$ \\
\hline & & DMFS & 1746 & 83 & $3-1850$ & 1.2 & 0.068 \\
\hline & & OS & 1402 & 93 & $2-2811$ & 1.15 & 0.2 \\
\hline
\end{tabular}




\begin{tabular}{|c|c|c|c|c|c|c|c|}
\hline Gene ID & Affimetrix ID & $\begin{array}{l}\text { Survival } \\
\text { outcome }\end{array}$ & $\begin{array}{c}\text { Number of } \\
\text { cases }\end{array}$ & Cut-off & $\begin{array}{l}\text { Expression range } \\
\text { of the probe }\end{array}$ & HR & LogrankP \\
\hline \multirow[t]{3}{*}{ S100A13 } & 202598-at & RFS & 3955 & 2672 & $286-20048$ & 0.94 & 0.25 \\
\hline & & DMFS & 1746 & 2743 & $475-20048$ & 0.83 & 0.059 \\
\hline & & OS & 1402 & 2607 & $475-15774$ & 0.89 & 0.27 \\
\hline \multirow[t]{3}{*}{ S100A14 } & 218677-at & RFS & 3955 & 1611 & $17-13313$ & 1.05 & 0.37 \\
\hline & & DMFS & 1746 & 1720 & $76-12605$ & 1.01 & 0.89 \\
\hline & & OS & 1402 & 1556 & $54-12605$ & 0.99 & 0.9 \\
\hline \multirow[t]{3}{*}{ S100A7A } & 232170-at & RFS & 3955 & 21 & $11-11406$ & 0.91 & 0.21 \\
\hline & & DMFS & 1746 & 31 & $1-11406$ & 1.31 & 0.1 \\
\hline & & OS & 1402 & 28 & $1-11406$ & 0.89 & 0.45 \\
\hline \multirow[t]{3}{*}{ S100A16 } & 227998-at & RFS & 3955 & 4529 & $239-18268$ & 1.23 & 0.008 \\
\hline & & DMFS & 1746 & 4829 & 683-16912 & 1.15 & 0.4 \\
\hline & & OS & 1402 & 4102 & $290-14364$ & 1.27 & 0.13 \\
\hline \multirow[t]{3}{*}{ S100B } & 209686-at & RFS & 3955 & 26 & $1-16122$ & 1.03 & 0.59 \\
\hline & & DMFS & 1746 & 28 & $1-3366$ & 0.89 & 0.22 \\
\hline & & OS & 1402 & 26 & $1-8014$ & 0.87 & 0.21 \\
\hline \multirow[t]{3}{*}{ S100G } & 207885-at & RFS & 3955 & 15 & $1-18316$ & 0.77 & $4.20 \mathrm{E}-06$ \\
\hline & & DMFS & 1746 & 15 & $1-13476$ & 0.92 & 0.42 \\
\hline & & OS & 1402 & 14 & $1-12435$ & 0.93 & 0.48 \\
\hline \multirow[t]{3}{*}{ S100P } & 204351-at & RFS & 3955 & 1117 & $3-46947$ & 1.5 & $2.60 \mathrm{E}-13$ \\
\hline & & DMFS & 1746 & 1113 & $6-29328$ & 1.36 & 0.0019 \\
\hline & & OS & 1402 & 1113 & $5-44788$ & 1.63 & $7.20 \mathrm{E}-16$ \\
\hline \multirow[t]{3}{*}{ S100Z } & 1554876-a-at-at & RFS & 3955 & 25 & $1-398$ & 0.72 & $4.80 \mathrm{E}-05$ \\
\hline & & DMFS & 1746 & 23 & $1-139$ & 0.7 & 0.03 \\
\hline & & OS & 1402 & 22 & $1-139$ & 0.88 & 0.44 \\
\hline
\end{tabular}

The prognostic value of individual S100 members evaluated in KM plotter database. For each S100 (identified with an Affimetrix ID) survival outcome was evaluated as Relapse Free Survival (RSF), Distant Metastasis Free Survival (DMFS) and Overall Survival (OS). Patients were splitted by median. Significant associations with prognosis are underlined in bold.

normal samples (55 analyses with up-regulation versus 27 analyses with down-regulation) and only S100A3 and S100A5 did not show differences between the analyzed dataset.

\section{Genomic alterations of S100 family members in breast cancer}

The OncoPrint tool of cBioPortal database [23] was used to query for alterations in $\mathrm{S} 100$ genes in breast cancer. As shown in Figure 2, the percentage of alterations spans from $0.3 \%$ to $19 \%$ for individual genes. In particular, the predominant pattern of amplification occurred in $19 \%, 18 \%$ and $17 \%$ of the S100 genes clustering into $1 \mathrm{p}$ chromosome, while a low percentage of alterations that include both gene amplifications and gene deletions were recorded for the other S100 genes.

\section{S100s gene expression is associated with clinical parameters}

We then used GOBO database, containing 1881 patient's data [23], to investigate the correlation between S100s gene expression and clinical parameters, including ER expression, tumor grade and molecular subtypes. We found significantly higher S100 expression levels (Figure 3 ) in ER negative tumors, in higher grade tumors and in basal-like and HER 2 tumors ( $<<0.0001$ according to oneway ANOVA), while lower S100 expression levels were found in Luminal A and Luminal B tumors. 


\section{Prognostic significance of S100 family members}

We also investigated the prognostic value of S100 family members in breast cancer using survival data, evaluated as Overall Survival (OS), Distant Metastasis Free Survival (DMFS) and Relapse Free Survival (RFS), of 5143 breast patients from Kaplan-Meier plotter database [24]. Firstly, the survival analysis was performed for each S100 gene, using a single Affimetrix ID probe. Results shown in Table 1, clearly indicate the association between the higher S100s expression with a worse prognosis (highlighted in red) or better prognosis (highlighted in black), pointed about the specific roles of single members as oncogenes or tumor suppressor genes. No association with survival data was recorded for S100A2, S100A3, S100A13, S100A14, S100A7A and S100B.

Interestingly, when the survival analysis was performed including all the S100s members, higher expression levels of S100s members, were significantly correlated with a shorter RSF, with HR $=1.83(1.56$ $2.14), \mathrm{p}=3.5 \mathrm{E}^{-14}$, DMFS with HR $=1.45(1.04-2), \mathrm{p}=$ 0.026 and OS with HR $=1.68(1.23-2.31), \mathrm{p}=0.0011$ (Figure 4). These results revealed that collectively S100 family members have a greater prognostic value than the individual genes.

Survival analyses were carried out on the subgroup of patients that in GOBO analysis showed significant S100 up-regulation. Intriguingly, up-regulated S100s were all significantly associated with worse RFS in the ER- and basal-like tumors (Figure 5), but not in HER2enriched group or in high grading, where the no statistical difference were recorded $(\mathrm{p}>0.05)$.

\section{Interaction network and pathway analysis of S100 family members}

We then analyzed the possible interactions between S100 family members with other genes via computational analysis by using three cross-platforms (STRING, GOBO and ONCOMINE), in order to reveal networks and pathways able to predict the underlying molecular mechanisms of S100-mediated roles in breast cancer. The predicted associations and the co-expressed genes for each S100 were queried to STRING, GOBO and ONCOMINE database, respectively, by using a combined score of $\geq$ 0.4. The associations in STRING include direct (physical) interactions, as well as indirect (functional) interactions, as long as both are specific and biologically meaningful. The co-expressed genes in GOBO and in ONCOMINE databases are calculated by Pearson correlation method. For each S100, the databases returned the predicted functional associations and the co-expressed genes, as reported in the pie chart of Figure 6. The lists of the S100-interactors from STRING, and the co-expressed genes from GOBO and ONCOMINE (Supplementary Tables 1-3) (containing 547,289 and 1261 unique proteins) were used to found functional enrichments in the S100-networks and clusterized through GO classification and KEGG pathways by using the String Analysis tool (Figure 6). Although each S100 was significantly associated with different genes in different databases, they are implicated in the same biological functions: infact, collectively, S100 affect inflammatory and immune response pathways, probably acting extracellularly, through the Toll-like and RAGE signaling.

Taking advantage of our previous proteomic data $[8$, $20,21]$, we performed a correlation analysis of the relative expression levels of each S100 protein spot identified in the proteomic maps (15 protein spots), with the global

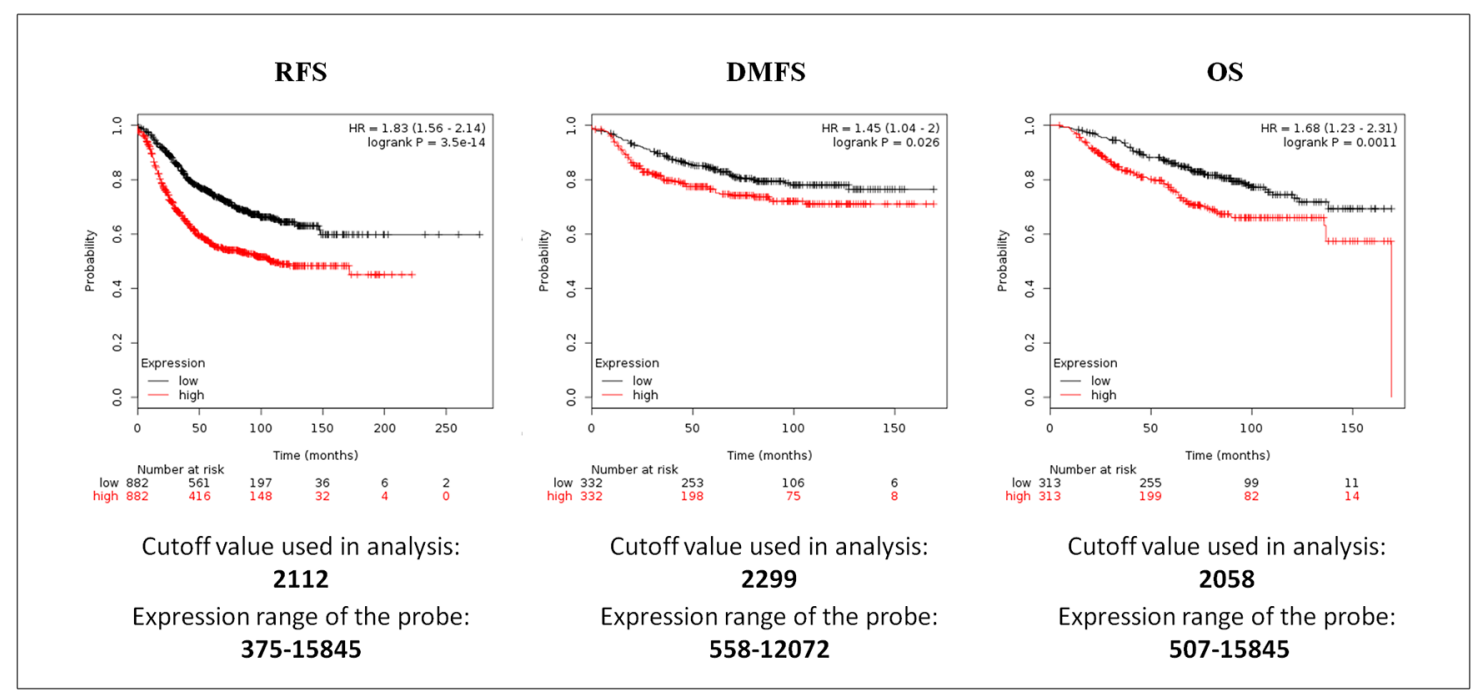

Figure 4: Survival analyses of S100 family members in breast cancer obtained from the Kaplan-Meier Plotter database. Survival was evaluated as RFS (relapse free survival), DMFS (distant metastasis free survival) and OS (overall survival). Patients were splitted into two groups by using the best cut-off of probe expression. 
ER-

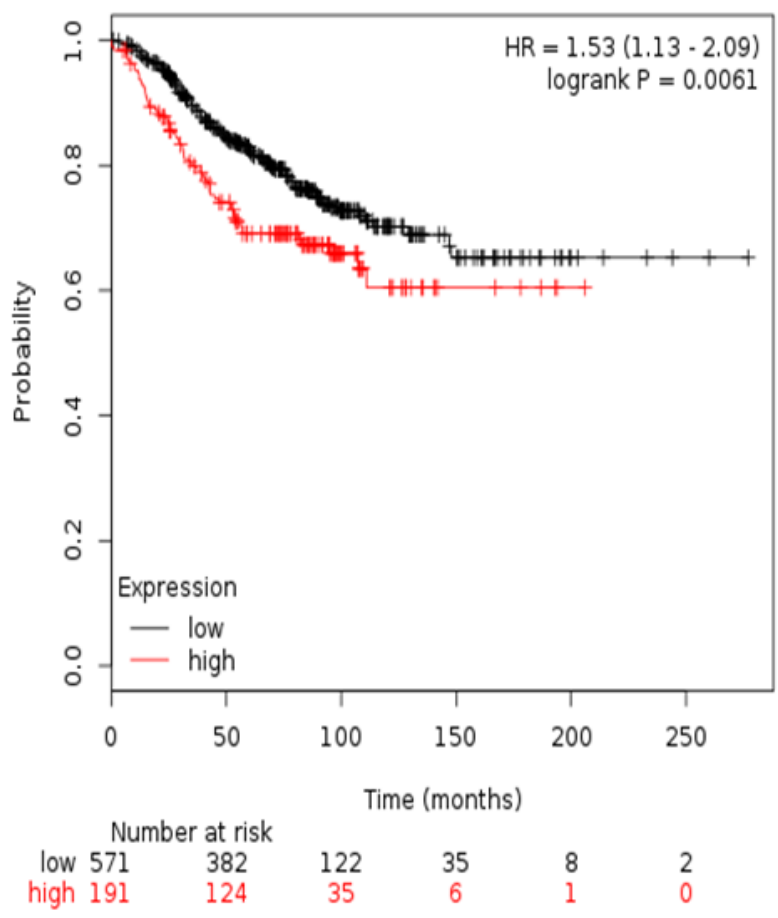

Basal

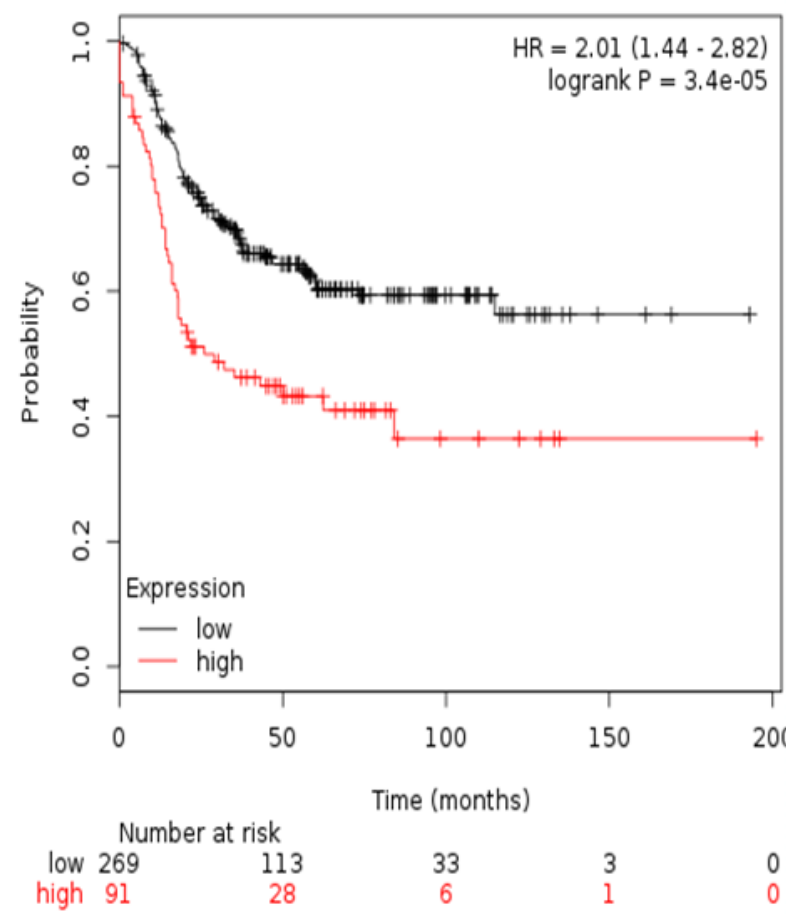

Grading 3

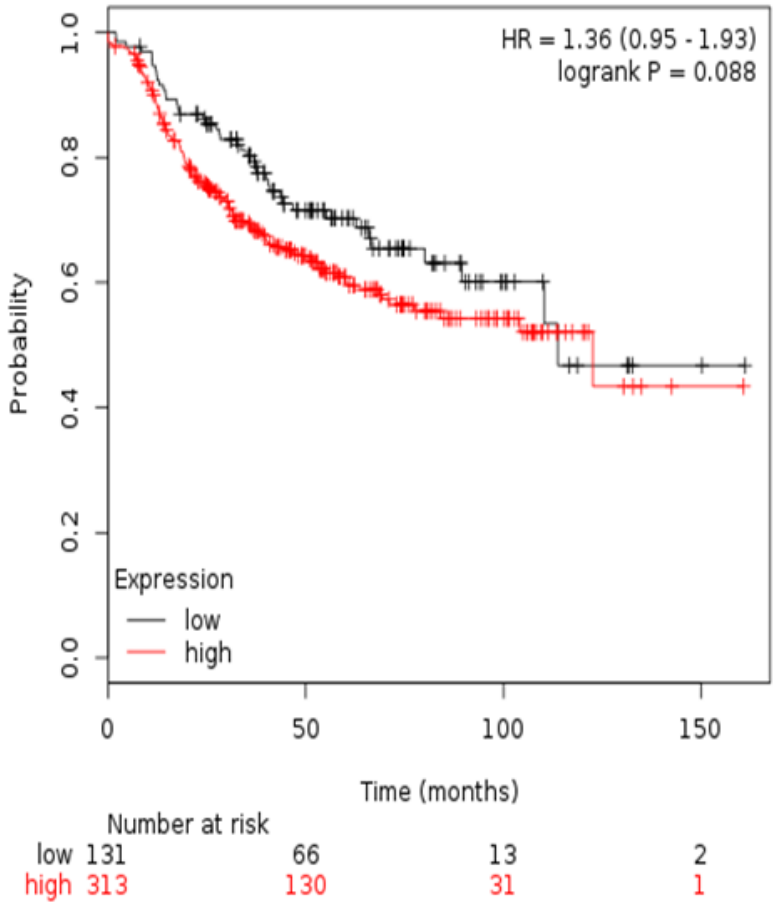

HER2

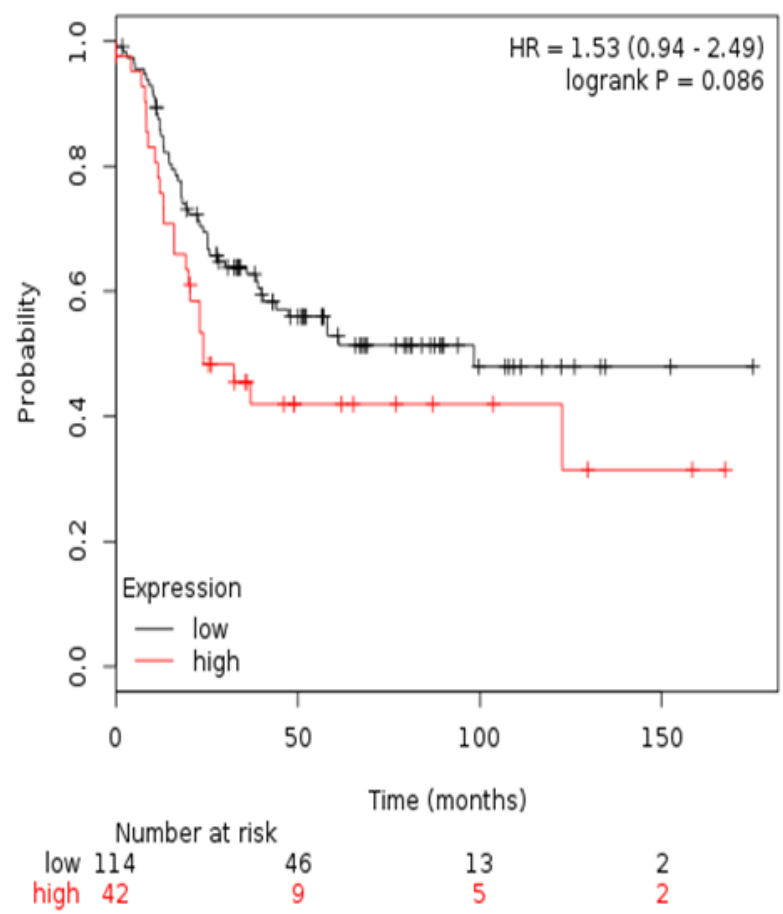

Figure 5: Survival analyses of S100 family members in breast cancer subgroups from the Kaplan-Meier Plotter database. Survival was evaluated as RFS (relapse free survival). Patients were splitted into two groups by using the best cut-off of probe expression. 


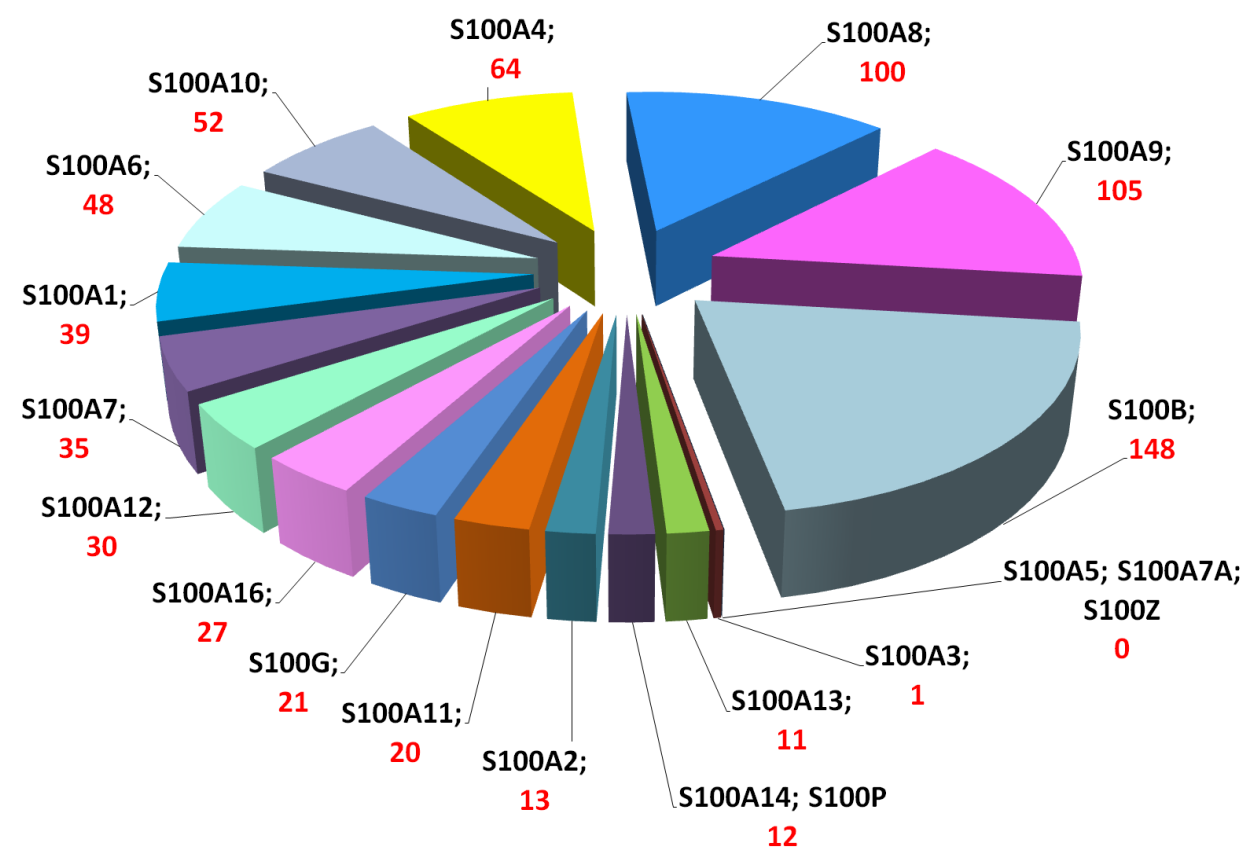

\begin{tabular}{|cccc|}
\hline \multicolumn{4}{c|}{ Biological Process (GO) } \\
\hline \hline Pathway ID & Pathway description & Count in gene set & False discovery rate \\
GO:0045087 & Innate immune response & 127 & $1.06 \mathrm{E}-54$ \\
GO:0006955 & Immune response & 144 & $1.00 \mathrm{E}-51$ \\
GO:0002376 & Immune system process & 172 & $3.71 \mathrm{E}-49$ \\
GO:0006952 & Defense response & 145 & $4.02 \mathrm{E}-49$ \\
GO:0080134 & Regulation of response to stress & 144 & $4.58 \mathrm{E}-48$ \\
\hline
\end{tabular}

\begin{tabular}{|c|c|c|c|}
\hline \multicolumn{4}{|c|}{ Molecular Function (GO) } \\
\hline Pathway ID & Pathway description & Count in gene set & False discovery rate \\
\hline GO:0005515 & Protein binding & 292 & $4.21 \mathrm{E}-61$ \\
\hline GO:0005102 & Receptor binding & 110 & $2.24 \mathrm{E}-33$ \\
\hline GO:0019899 & Enzyme binding & 103 & $4.57 \mathrm{E}-22$ \\
\hline GO:0005126 & Cytokine receptor binding & 29 & $5.99 \mathrm{E}-11$ \\
\hline GO:0050786 & RAGE receptor binding & 8 & $4.92 \mathrm{E}-10$ \\
\hline
\end{tabular}

\begin{tabular}{|c|c|c|c|}
\hline \multicolumn{4}{|c|}{ Cellular Component (GO) } \\
\hline Pathway ID & Pathway description & Count in gene set & False discovery rate \\
\hline GO:0044421 & Extracellular region part & 216 & $5.01 \mathrm{E}-34$ \\
\hline GO:0005829 & Cytosol & 190 & $6.56 \mathrm{E}-30$ \\
\hline GO:0070062 & Extracellular exosome & 174 & $3.21 \mathrm{E}-29$ \\
\hline GO:0005576 & Extracellular region & 222 & $1.32 \mathrm{E}-26$ \\
\hline GO:0031988 & Membrane-bounded vesicle & 191 & $1.90 \mathrm{E}-26$ \\
\hline
\end{tabular}

\begin{tabular}{|cccc|}
\hline \multicolumn{4}{|c|}{ KEGG Pathways } \\
\hline \hline Pathway ID & Pathway description & Count in gene set & False discovery rate \\
5205 & Proteoglycans in cancer & 48 & $8.94 \mathrm{E}-28$ \\
5200 & Pathways in cancer & 54 & $1.27 \mathrm{E}-25$ \\
4915 & Estrogen signaling pathway & 27 & $1.56 \mathrm{E}-19$ \\
4660 & T cell receptor signaling pathway & 27 & $6.16 \mathrm{E}-19$ \\
4620 & Toll-like receptor signaling pathway & 26 & $1.42 \mathrm{E}-17$ \\
4012 & ErbB signaling pathway & 24 & $1.5 \mathrm{E}-17$ \\
\hline
\end{tabular}

(Continued) 
B

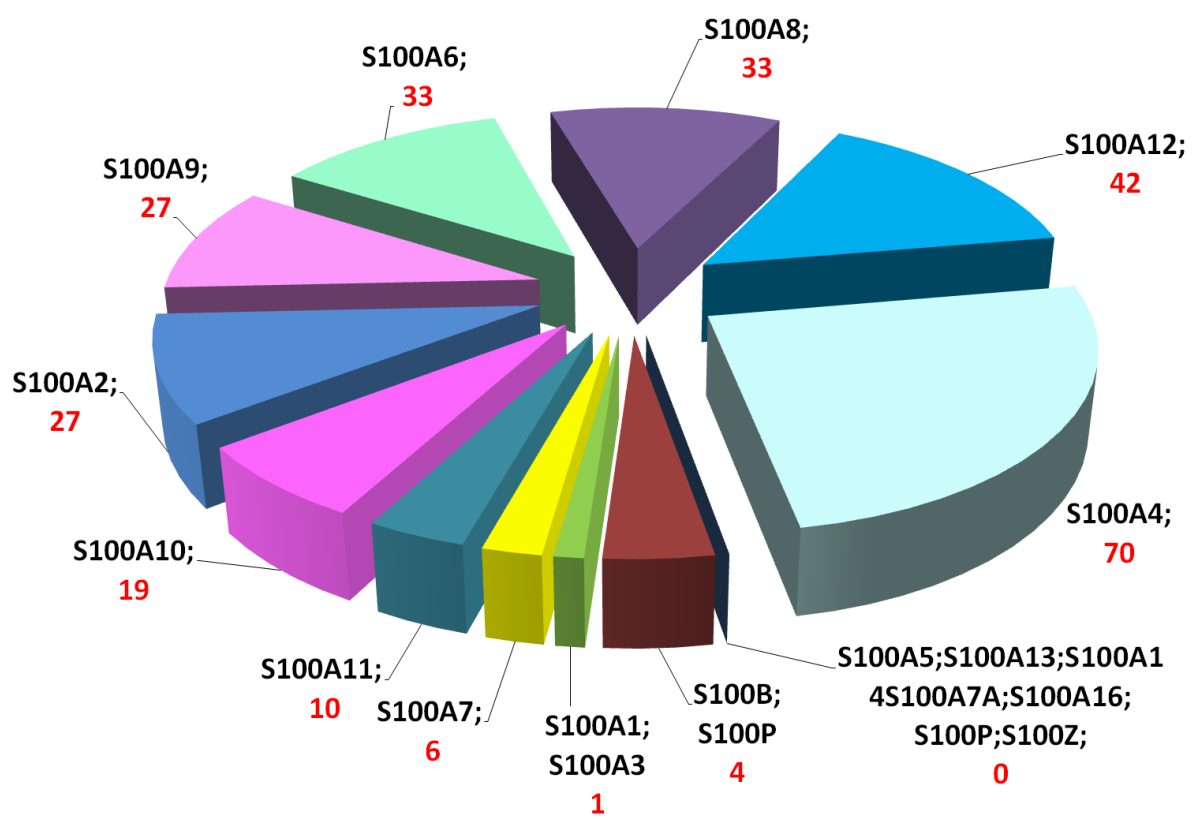

\begin{tabular}{|cccc|}
\hline \multicolumn{4}{c|}{ Biological Process (GO) } \\
\hline \hline Pathway ID & Pathway description & Count in gene set & False discovery rate \\
GO:0006955 & Immune response & 56 & $4.81 \mathrm{E}-14$ \\
GO:0006952 & Defense response & 54 & $8.96 \mathrm{E}-12$ \\
GO:0045087 & Innate immune response & 43 & $2.32 \mathrm{E}-11$ \\
GO:0002376 & Immune system process & 60 & $2.81 \mathrm{E}-09$ \\
GO:0006954 & Inflammatory response & 26 & $1.39 \mathrm{E}-08$ \\
\hline
\end{tabular}

\begin{tabular}{|c|c|c|c|}
\hline \multicolumn{4}{|c|}{ Molecular Function (GO) } \\
\hline Pathway ID & Pathway description & Count in gene set & False discovery rate \\
\hline GO:0005509 & Calcium ion binding & 36 & $3.41 \mathrm{E}-10$ \\
\hline GO:0050786 & RAGE receptor binding & 7 & $2.95 \mathrm{E}-09$ \\
\hline GO:0005200 & Structural constituent of cytoskeleton & 14 & $2.10 \mathrm{E}-08$ \\
\hline GO:0005515 & Protein binding & 99 & $2.40 \mathrm{E}-08$ \\
\hline GO:0005102 & Receptor binding & 36 & $1.78 \mathrm{E}-05$ \\
\hline
\end{tabular}

\begin{tabular}{|cccc|}
\hline \multicolumn{4}{c|}{ Cellular Component (GO) } \\
\hline \hline Pathway ID & Pathway description & Count in gene set & False discovery rate \\
GO:0044421 & Extracellular region part & 110 & $3.69 \mathrm{E}-20$ \\
GO:0005576 & Extracellular region & 120 & $6.84 \mathrm{E}-20$ \\
GO:0031988 & Membrane-bounded vesicle & 100 & $1.74 \mathrm{E}-17$ \\
GO:0070062 & Extracellular exosome & 89 & $1.74 \mathrm{E}-17$ \\
GO:0031982 & Vesicle & 101 & $3.68 \mathrm{E}-17$ \\
\hline
\end{tabular}

\begin{tabular}{|cccc|}
\hline \multicolumn{4}{c|}{ KEGG Pathways } \\
\hline \hline Pathway ID & Pathway description & Count in gene set & False discovery rate \\
4145 & Phagosome & 13 & $7.06 \mathrm{E}-06$ \\
5150 & Staphylococcus aureus infection & 8 & $2.83 \mathrm{E}-05$ \\
4666 & Fc gamma R-mediated phagocytosis & 8 & 0.000708 \\
4380 & Osteoclast differentiation & 8 & 0.00608 \\
4620 & Toll-like receptor signaling pathway & 7 & 0.00749 \\
5205 & Proteoglycans in cancer & 9 & 0.00222 \\
\hline
\end{tabular}

(Continued) 
C

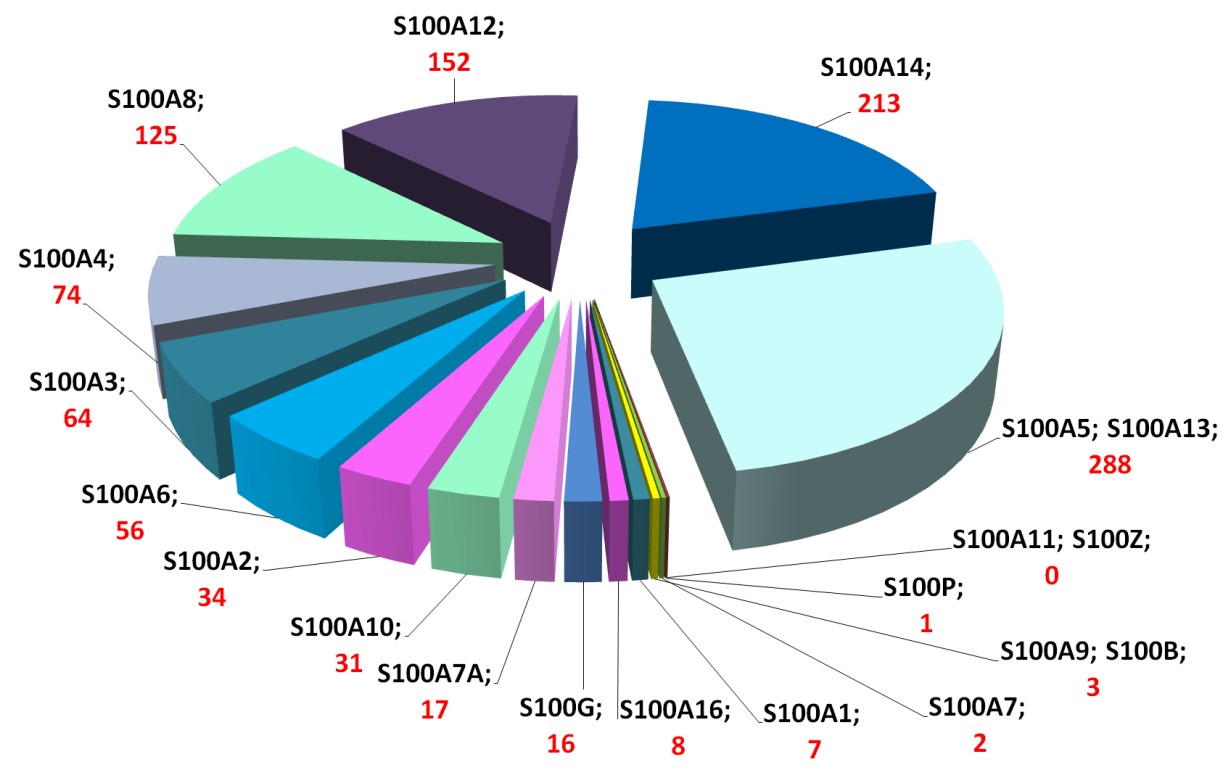

\begin{tabular}{|cccc|}
\hline \multicolumn{4}{c|}{ Biological Process (GO) } \\
\hline \hline Pathway ID & Pathway description & Count in gene set & False discovery rate \\
GO:0050896 & Response to stimulus & 527 & $7.37 \mathrm{E}-25$ \\
GO:0002376 & Immune system process & 218 & $2.50 \mathrm{E}-23$ \\
GO:0006955 & Immune response & 156 & $5.62 \mathrm{E}-19$ \\
GO:0007154 & Cell communication & 398 & $2.40 \mathrm{E}-18$ \\
GO:0006952 & Defense response & 158 & $3.16 \mathrm{E}-17$ \\
\hline
\end{tabular}

\begin{tabular}{|cccc|}
\hline \multicolumn{4}{c|}{ Molecular Function (GO) } \\
\hline \hline Pathway ID & Pathway description & Count in gene set & False discovery rate \\
GO:0005515 & Protein binding & 378 & $7.64 \mathrm{E}-17$ \\
GO:0005102 & Receptor binding & 123 & $1.49 \mathrm{E}-11$ \\
GO:0005509 & Calcium ion binding & 76 & $3.84 \mathrm{E}-06$ \\
GO:0005539 & Glycosaminoglycan binding & 32 & $1.59 \mathrm{E}-05$ \\
GO:0050786 & RAGE receptor binding & 7 & $2.10 \mathrm{E}-05$ \\
\hline
\end{tabular}

\begin{tabular}{|cccc|}
\hline \multicolumn{4}{c|}{ Cellular Component (GO) } \\
\hline \hline Pathway ID & Pathway description & Count in gene set & False discovery rate \\
GO:0044459 & Plasma membrane part & 222 & $6.5 \mathrm{E}-16$ \\
GO:0005576 & Extracellular region & 359 & $1.59 \mathrm{E}-15$ \\
GO:0005615 & Extracellular space & 143 & $1.22 \mathrm{E}-14$ \\
GO:0005887 & Integral component of plasma membrane & 160 & $2.67 \mathrm{E}-14$ \\
GO:0005886 & Plasma membrane & 358 & $4.13 \mathrm{E}-14$ \\
\hline
\end{tabular}

\begin{tabular}{|cccc|}
\hline \multicolumn{4}{|c|}{ KEGG Pathways } \\
\hline \hline Pathway ID & Pathway description & Count in gene set & False discovery rate \\
5200 & Pathways in cancer & 46 & $2.78 \mathrm{E}-06$ \\
4062 & Chemokine signaling pathway & 29 & $5.36 \mathrm{E}-05$ \\
4640 & Hematopoietic cell lineage & 18 & $1.25 \mathrm{E}-04$ \\
5340 & Primary immunodeficiency & 11 & $1.80 \mathrm{E}-04$ \\
4080 & Neuroactive ligand-receptor interaction & 35 & $2.78 \mathrm{E}-04$ \\
4620 & Toll-like receptor signaling pathway & 15 & 0.0098 \\
\hline
\end{tabular}

Figure 6: S100-associated genes analyzed with STRING (A), GOBO (B) and ONCOMINE (C) databases. Graphs represent the number of associated genes (STRING) and co-expressed genes (GOBO and ONCOMINE) for each S100. The tables represent the 5 top significantly biological processes, molecular functions, cellular components and key pathways evaluated by using the String Analysis tool. 
protein complement (453 protein spots identified by mass spectrometry) by using a pearson correlation statistical test. Figure 7A shows a proteomic map representative of breast cancer surgical tissue, where the 453 protein spots identified are marked with red asterisks and S100-protein spots are highlighted. Different S100-isoforms (S100A6 two isoforms, S100A7 two isoforms, S100A11 three isoforms, S100A13 two isoforms) are labeled by alphabetical letters starting from the more acidic one. As reported in Figure $7 \mathrm{~B}$, each S100 protein and isoform was correlated with a different set of proteins, suggesting distinctive roles for $\mathrm{S} 100$ proteins and isoforms. Specifically, among the 453 protein spots identified in our proteomic maps (corresponding to 271 genes), 236 protein spots (corresponding to $52 \%$ of the total proteins), were significantly correlated with at least a S100 protein spot. Figure 7C shows, in particular, the number of protein spots correlated with single or multiple S100 proteins. To give greater strength to the results we have chosen to carried out the functional classification of S100-correlated proteins with the protein spots, showing significant correlation with at least five S100-protein spots, listed in Figure 7D. Functional enrichments in the S100-
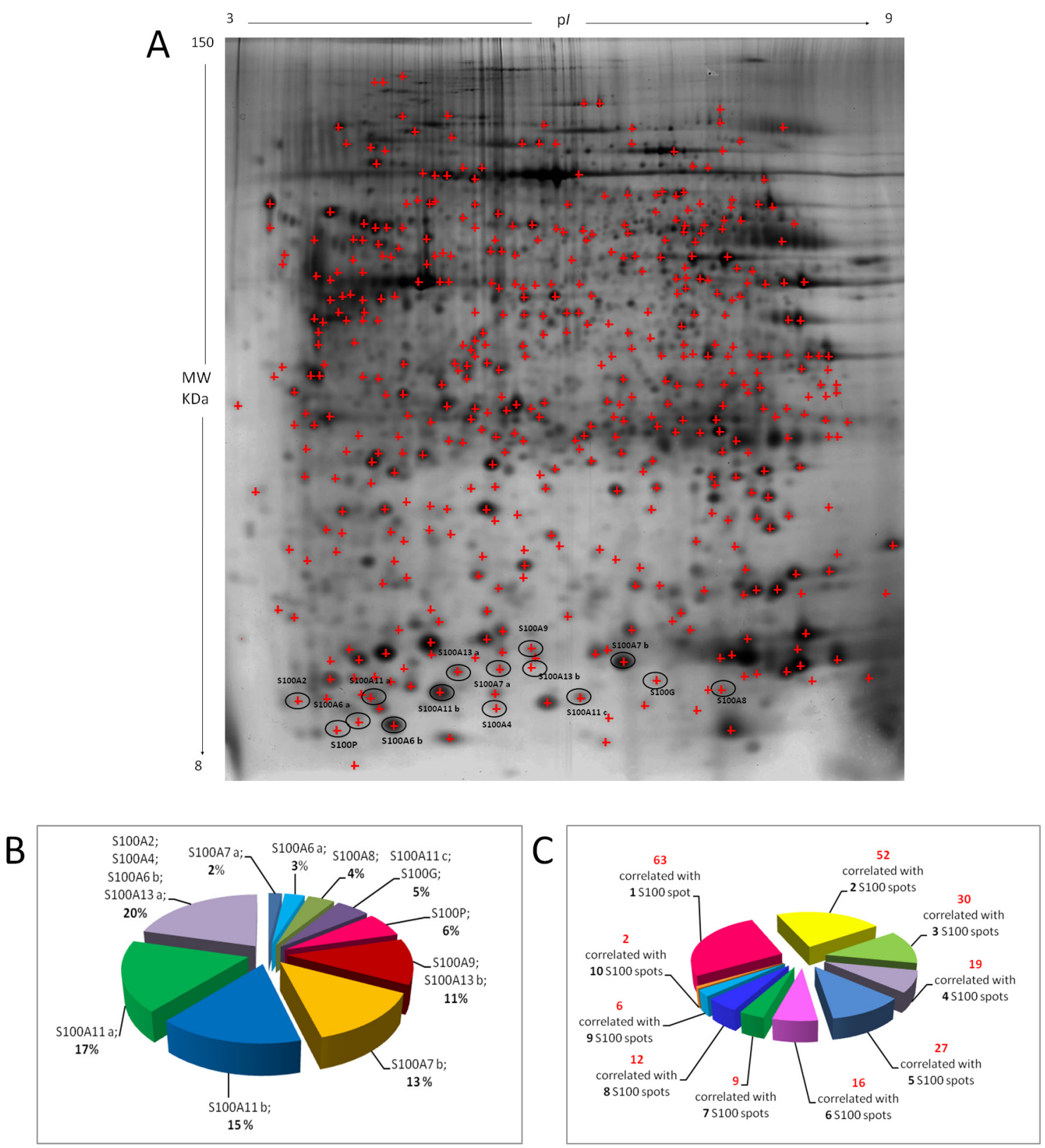

Figure 7: Proteomic correlations with S100 proteins. (A) Prototype of a breast cancer tissue. Red asterisks indicate the 453 protein spots identified by MALDI-TOF mass spectrometry. The S100-protein spots are highlighted and the different isoforms labeled with alphabetical letters starting from the more acidic one. (B) Pie-chart showing for each S100 protein the percentage of the correlated proteins, among the 453 identified. (C) Pie-chart showing the number of protein spots correlated with single or multiple S100 proteins. 


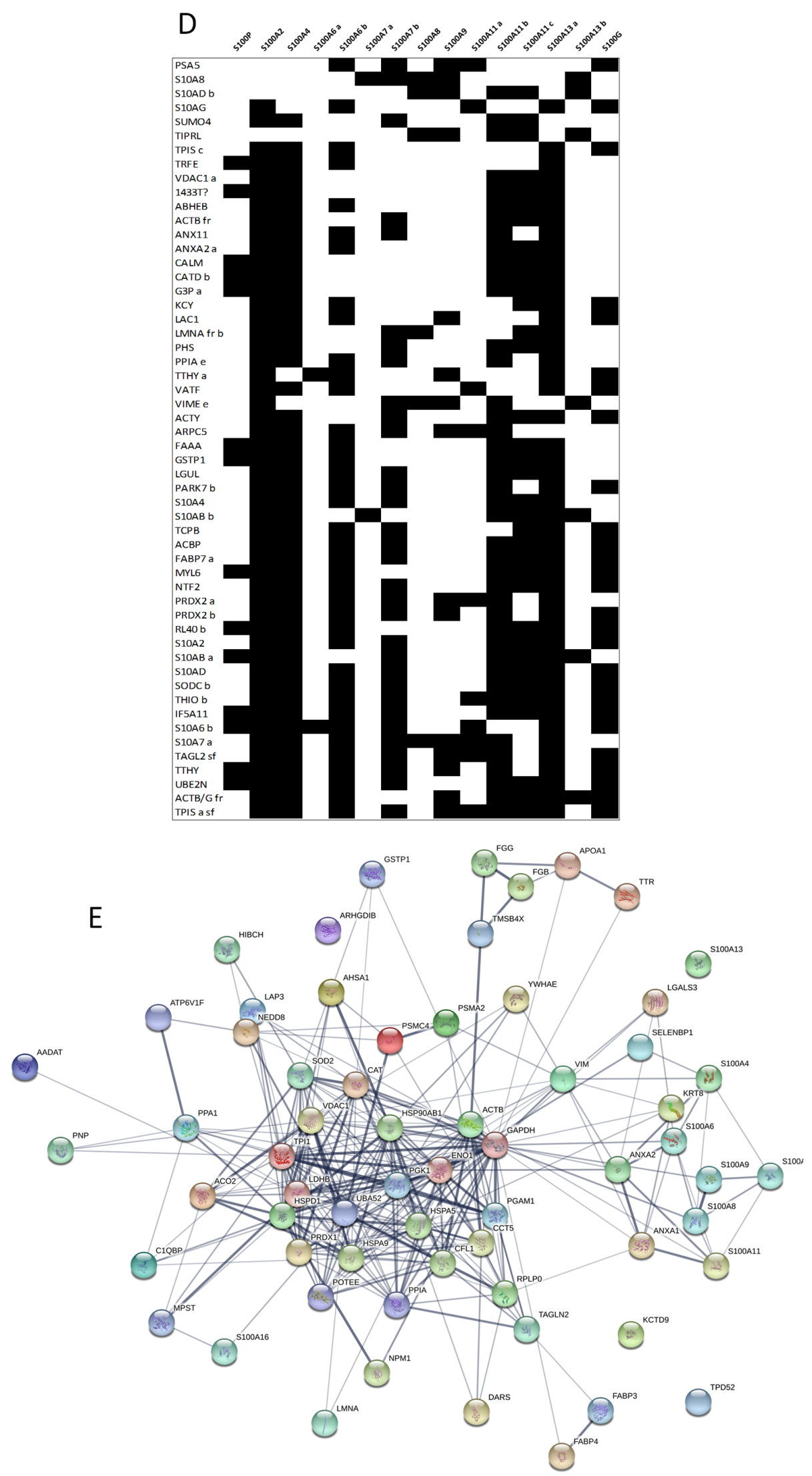

Figure 7 (Continued): (D) Histogram of 64 unique proteins showing significant correlation with at least five S100-protein spots. Black boxes represent the correlated proteins. (E) Interactome derived from the proteins listed in histogram 7D by using String database. 


\begin{tabular}{|c|c|c|c|}
\hline \multicolumn{4}{|c|}{ Biological Process (GO) } \\
\hline Pathway ID & Pathway description & Count in gene set & False discovery rate \\
\hline GO:0019674 & NAD metabolic process & 7 & $2.97 \mathrm{E}-06$ \\
\hline GO:0002576 & platelet degranulation & 7 & $1.18 \mathrm{E}-05$ \\
\hline GO:0042981 & regulation of apoptotic process & 19 & $1.18 \mathrm{E}-05$ \\
\hline GO:0002376 & immune system process & 22 & $1.28 \mathrm{E}-05$ \\
\hline GO:0006955 & immune response & 18 & $1.28 \mathrm{E}-05$ \\
\hline
\end{tabular}

\begin{tabular}{|c|c|c|c|}
\hline \multicolumn{4}{|c|}{ Molecular Function (GO) } \\
\hline \hline Pathway ID & Pathway description & Count in gene set & False discovery rate \\
\hline GO:0050786 & RAGE receptor binding & 5 & $6.56 \mathrm{E}-08$ \\
\hline GO:0044822 & poly(A) RNA binding & 17 & $5.05 \mathrm{E}-05$ \\
\hline GO:0005509 & calcium ion binding & 12 & $4.39 \mathrm{E}-04$ \\
\hline GO:0003723 & RNA binding & 19 & $6.59 \mathrm{E}-05$ \\
\hline GO:0044548 & S100 protein binding & 3 & $1.50 \mathrm{E}-03$ \\
\hline
\end{tabular}

\begin{tabular}{|c|c|c|c|}
\hline \multicolumn{4}{|c|}{ Cellular Component (GO) } \\
\hline \hline Pathway ID & Pathway description & Count in gene set & False discovery rate \\
\hline GO:0070062 & extracellular exosome & 53 & $3.58 \mathrm{E}-34$ \\
\hline GO:0031988 & membrane-bounded vesicle & 54 & $4.19 \mathrm{E}-31$ \\
GO:0044421 & extracellular region part & 52 & $5.09 \mathrm{E}-27$ \\
\hline GO:0005576 & extracellular region & 52 & $2.13 \mathrm{E}-23$ \\
\hline GO:0005615 & extracellular space & 24 & $8.40 \mathrm{E}-12$ \\
\hline
\end{tabular}

\begin{tabular}{|c|c|c|c|}
\hline \multicolumn{4}{|c|}{ KEGG Pathways } \\
\hline Pathway ID & Pathway description & Count in gene set & False discovery rate \\
\hline 1230 & Biosynthesis of amino acids & 6 & $2.37 \mathrm{E}-05$ \\
\hline 1200 & Carbon metabolism & 6 & $1.13 \mathrm{E}-04$ \\
\hline 10 & Glycolysis / Gluconeogenesis & 5 & $1.17 \mathrm{E}-04$ \\
\hline
\end{tabular}

Figure 7 (Continued): (F) Tables reporting the 5 top significantly biological processes, molecular functions, cellular components and key pathways evaluated by using the String Analysis tool.

correlated proteins were analyzed by using the String Analysis tool and clusterized through GO classification and KEGG pathways. Interestingly, the interactome analysis (Figure 7E) showed that the S100-correlated proteins contained more interactions among themselves than what would be expected for a random set of proteins of similar size, (number of edges: 285, expected number of edges: 111; PPI enrichment $\mathrm{p}$-value: $<1.0 \mathrm{e}^{-16}$ ) indicating they were at least partially biologically connected. Again, the biological connection concerned the implication of the immune response, probably through the RAGE receptors signaling. Moreover, S100- correlated proteins affect NAD metabolic and apoptotic processes (Figure 7F).

\section{S100 expression in laser captured microdissection (LCM) microarray data set}

In order to verify if $\mathrm{S} 100 \mathrm{~s}$ are expressed by epithelial cells, stromal cells or both, we analyzed the public microarray data set from GEO (GSE10797), containing the expression data from epithelial and stromal cells that were laser captured from invasive breast cancer $(n=28)$ [25]. For each $\mathrm{S} 100$ probe, the expression values were analyzed by GEO2R tool. As reported in the Figure
8 , no significant differences were observed between the epithelial and stromal compartments. As evident from high values of standard deviation, S100 expression levels are more variable between different tumors.

\section{DISCUSSION}

Accumulating evidences have demonstrated that S100 family members play a critical role in cancer development. Several reports deal with the correlation or the involvement of individual S100 members in cancer [26-35], but their possible coordination and collective role, as well as the functional implications of their expression are still poorly known. In this study, we used a systematic multiomics approach to assess the role of S100 family members in BC. In comparison to normal tissues, the transcriptional levels of S100 members are robustly upregulated although in some cases a down regulation was found, indicating that S100 could act both as oncogenes or tumor suppressor genes, and exert both pro- and anti- tumorigenic actions depending on the tumor type. For example, the over-expression of S100A2, S100A3, S100A6, S100A8/A9, S100A11 and S100A14 have been documented in several cancer types. Conversely, under-expression of these proteins has been 
found in other cancer types [36]. Moreover, has been demonstrated that S100A2 expression is suppressed early during lung carcinogenesis [37].

By using cBioPortal database we verified if the deregulated expression of S100 family members in breast cancer could be caused by genetic alterations. Interestingly, the results showed that the predominant pattern of amplification (about 18\%) occurred in the S100 genes clustering into $1 \mathrm{p}$ chromosome, while a low percentage of alterations that include both gene amplifications and gene deletions were recorded for the other S100 genes. Recently, it was reported that chromosome 1q21.3 amplification is a trackable biomarker and actionable target for breast cancer recurrence [38], so it is possible to explain these evidences also in consideration of the deregulated S100 expression.

We also investigated the prognostic value of S100 family members in BC by using KM plotter. Among them, 14 members were significantly associated with prognosis, evaluated as different survival, and only S100A2, S100A3, S100A13, S100A14, S100A7A and S100B were not associated with prognosis. These results are in agreement with the results obtained by Zhang et al., [35] about the prognostic values of S100 with the Overall Survival, and add new information about the individual S100 protein prognostic significance evaluated as Relapse Free Survival and Distant Metastasis Free Survival. Moreover, when the survival analysis was performed including all the S100 members, higher expression levels of S100s were significantly correlated with a shorter survival, indicating that S100 family members have collectively a greater prognostic value than the individual genes. Although the functions of S100 proteins have been extensively studied and the functional modes of S100 proteins can be intracellular, extracellular, or a combination of both [39], the molecular mechanisms by which S100 proteins contribute to cancer progression are not fully understood. The pathway and network-based analysis using data mining and a new correlation analysis with our previous proteomic data revealed that collectively S100-associated proteins are involved in relevant biological pathways correlated to immune response and inflammation. Our results are in agreement with many studies showing that, during infection, certain S100 proteins act as damage-associated molecular patterns (DAMPs) and interact with pattern recognition receptors to modulate inflammatory responses, [40, 41]. In addition, these inflammatory $\mathrm{S} 100$ proteins have potent antimicrobial properties and are essential components of the immune response against invading pathogens. Moreover, the creation of a pre-metastatic environment depends on the activation of inflammatory pathways [42] in the surrounding tissue, increasing the "mobility" of cells and thus facilitating the development of distant metastases or modulation of cell growth and differentiation [43]. So far, for several S100 members (i.e S100A7, S100A8, S100A9, and S100A12) a role in innate immunity has been demonstrated [44-46], while for S100A15, which is highly homologous to S100A7 (93\% identity), a role in innate immunity is proposed as well [47]. Moreover, the association of S100 with autoimmune diseases has been known since long time in different inflammatory conditions. For example, S100A4 is involved in autoimmune pancreatitis [48], S100A11, S100A8 and S100A9 in rheumatoid arthritis $[49,50]$, S100A1 in hypoxia-

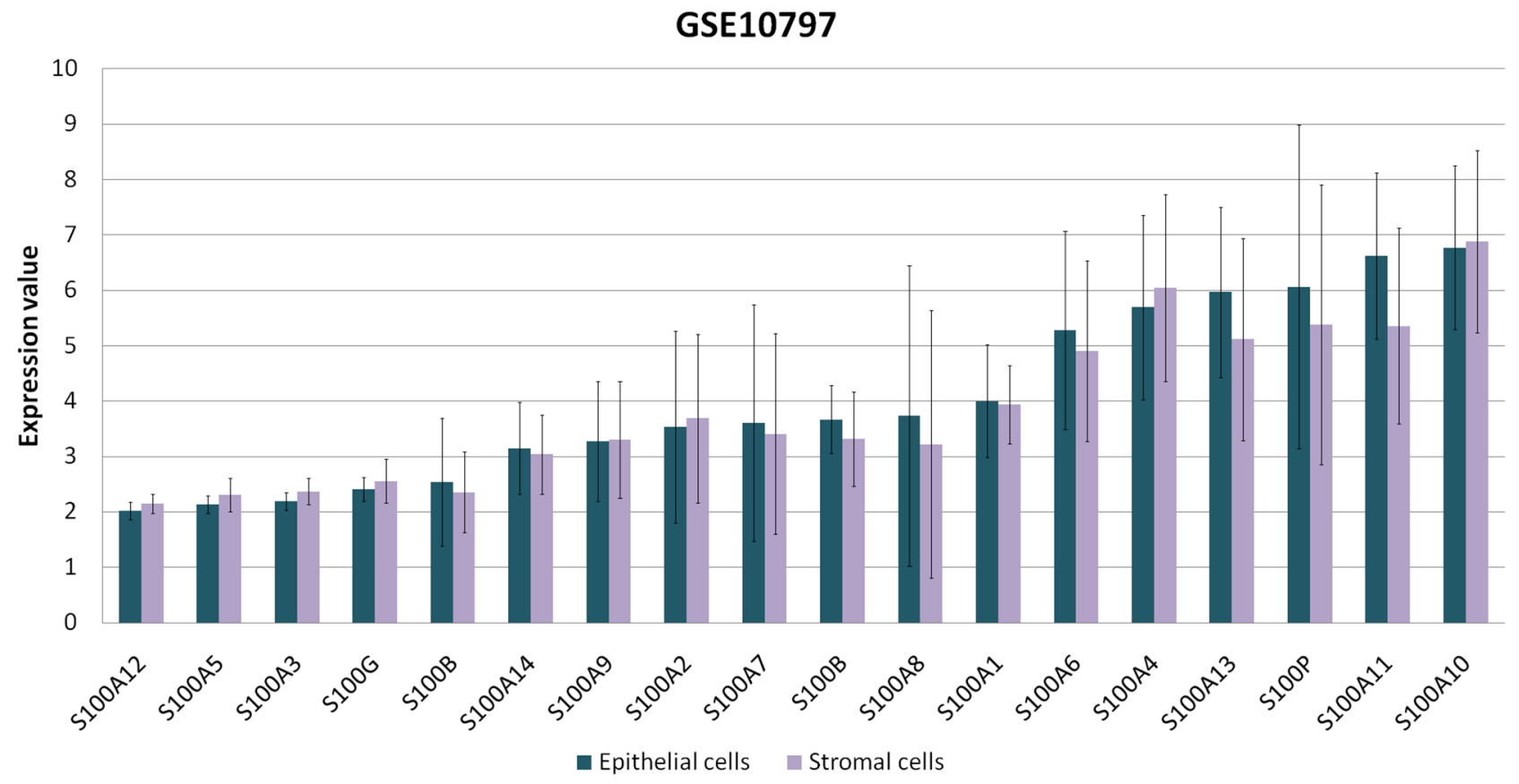

Figure 8: S100s expression values between epithelial and stromal cells. Expression levels of S100 proteins derived from the available microarray data set (GSE10797) in GEO Dataset and analyzed by GEO2R tool. 
induced inflammatory response in cardiomyocytes [51], S100A12 in Crohn's disease [52], S100A7 and S100A7A in psoriasis [53], S100A8, S100A9 and S100A12 in systemic lupus erythematosus [54]. Nevertheless, the exact mechanism leading to S100-induced inflammatory reactions has not been identified. Probably, the binding to specific receptors, RAGEs (receptor for advanced glycation end products) and Toll-like receptors (TLR4 and TLR2) mediates the proinflammatory axis. Infact, upon stimulation with proinflammatory cytokines $\mathrm{S} 100$ proteins have been shown to be strongly upregulated, and in turn, S100 upregulation determines the overproduction of cytokines and interleukins [54-56]. This proinflammatory microenvironment promotes the secretion of various cytokines and growth factors into the tumor microenvironment. Recently growing evidence suggests that the tumor microenvironment plays a central role in the promotion of tumor metastasis [57]. S100 proteins, infact, can be considered as inducer of a cytokine network enabling tumor cells to engage angiogenic and migratory pathways [55], modulating the ECM molecules and the ECM dinamycs. For example, extracellular S100A4 stimulates invasive growth of mouse endothelial cells and modulates MMP-2, MMP-9 and MMP-13 matrix metalloproteinase activity [58, 59], while S100A7 modulates MMP-9 expression [60]; S100A14 protein is involved in cell invasion by affecting the expression and the function of matrix metalloproteinase MMP-2 [61]. Interestingly, by using the expression data from LCM between cancer epithelial and stromal cells we verified that S100 proteins are expressed in both cancer and stromal cells. Elucidation of these mechanisms would have a significant impact on understanding the pathogenesis of inflammation-associated tumors and in particular of breast cancer, and could aid progress in the development of more effective cancer therapies.

\section{MATERIALS AND METHODS}

\section{ONCOMINE database analysis}

ONCOMINE (http://www.oncomine.org), is an online microarray database, able to analyze the mRNA expression differences between tumor and normal tissues in common human cancers. For each cancer and gene, the thresholds were set as follows: p-value: 0.01 ; fold change: 2; gene rank: 10\%; analysis type: cancer vs. normal analysis; data type: mRNA.

\section{GOBO database analysis}

GOBO database (http://co.bmc.lu.se/gobo), allow a rapid assessment of gene expression levels, identification of co-expressed genes and association with outcome for single genes, gene sets or gene signatures in an 1881-sample breast cancer data set, generated on Affymetrix U133A microarrays [55].

\section{Kaplan-Meier Plotter database analysis}

The KM Plotter database (http://kmplot.com/ analysis/), able to assess the effect of 54,675 genes on survival using 10,461 cancer samples, including 5,143 breast, was applied to evaluate the prognostic values of S100 family members in breast cancer [24]. The desired probes ID were entered into the database by using the multigene classifier. Patients were splitted into high and low expression group by the median values of mRNA expression or by the best cut-off, as indicated.

\section{cBioPortal database analysis}

The cBioPortal (http://www.cbioportal.org) for Cancer Genomics provides visualization, analysis and download of large-scale cancer genomics data sets [56].

\section{STRING database analysis}

STRING (https://string-db.org) is a database of known and predicted protein-protein interactions. The interactions include direct (physical) and indirect (functional) associations; they stem from computational prediction, from knowledge transfer between organisms, and from interactions aggregated from other (primary) databases analysis [57].

\section{Proteomics of breast cancer tissues and correlation analysis}

Proteomic analysis was performed on 100 breast cancer tissues following surgical interventions during the years 2003-2007 at the "La Maddalena" Hospital of Palermo, as previously described [8]. Briefly, surgical samples were homogenated overnight at $4 \mathrm{C}$ with RIPA buffer, containing $50 \mathrm{mM}$ Tris $\mathrm{pH} 7.5,0.1 \%$ Nonidet P-40, $0.1 \%$ deoxycholate, $150 \mathrm{mM} \mathrm{NaCl}, 4 \mathrm{mM}$ EDTA and a mixture of protease and phosphatase inhibitors $(0.01 \%$ aprotinin, $10 \mathrm{mM}$ sodium pyrophosphate, $2 \mathrm{mM}$ sodium orthovanadate, $1 \mathrm{mM}$ PMSF). After centrifugation, the obtained supernatant was dialyzed against ultrapure distilled water, lyophilized and resuspended in ISOT buffer (4\% CHAPS, $40 \mathrm{mM}$ Trizma base, $65 \mathrm{mM}$ DTE and a trace of bromophenol blue in $8 \mathrm{M}$ urea). Aliquots containing $45 \mu \mathrm{g}$ of total proteins were rehydrated in rehydratation buffer containing $8 \mathrm{M}$ urea, 2\% CHAPS, $10 \mathrm{mM}$ DTE and $0.5 \%$ carrier ampholytes (Resolyte $3.5-10$ ). The first electroforetic separation of 2D-IPG was performed on 18 $\mathrm{cm}$ long strips with a $\mathrm{pH}$ range $3.0-10$. The strips were then equilibrated in a solution containing $50 \mathrm{mM}$ Tris- $\mathrm{HCl} \mathrm{pH}$ 6.8, $6 \mathrm{M}$ urea, $0.5 \% \mathrm{SDS}, 30 \%$ Glycerol, $130 \mathrm{mM}$ DTE and $135 \mathrm{mM}$ Iodoacetamide and then separated on 9-16\% linear gradient polyacrylamide gels (SDS-PAGE) with a constant current of $20 \mathrm{~mA} /$ gel $[58,59]$. The gels were silver stained and analyzed with the dedicated ImageMaster 2D Platinum software. Protein identity was assigned by peptide mass 
fingerprinting using the Voyager DE- MALDI-TOF mass spectrometer as described [7, 9, 60, 61]. The expression level of the protein spots were calculated as the volume of the spots (i.e., integration of optical density over the spot area), relative to the sum of the volume of all spots on each gel $(\% \mathrm{Vol})$. Measurements of relative expression levels of individual protein spots were normalized in each proteomic map for actin content $(\mathrm{N} \% \mathrm{~V})$, as previously reported [20]. Correlation analysis with the collective profile of cancer patients proteomics was performed using the Pearson correlation test. Correlation coefficient $\geq 0.4$ and $p<0.05$ was considered significant.

\section{CONCLUSIONS}

This study confirmed the prognostic value of mRNA expression of the S100 family members in breast cancer and pointed to the molecular mechanism through which S100 affects cancer progression, probably regulating innate immune response and inflammation pathways. The extracellular activities of S100 proteins depend on the cellspecific expression patterns, the specific targets and the local microenvironment as well. For the first time, an integrated multiomics approach performed on S100 family members, allowed to extrapolate new insight regarding the collective role of S100 in BC. Interestingly, although is known that the correlation between mRNA and protein abundances are often poor in the cells, by using large-scale dataset derived from transcriptional and proteomic data, we obtained a good convergence between S100-regulated pathways. Further studies will be necessary to understand the role of epigenetic changes and the different protein-isoforms.

\section{ACKNOWLEDGMENTS}

This work was partially supported by Grants from University of Palermo (n.2014-ATE-0185) to S.F. and P.C. and by State-made contribution (5 X 1000) for distinguished no profit research associations.

\section{CONFLICTS OF INTEREST}

Authors declare no conflicts of interest.

\section{REFERENCES}

1. DeSantis C, Ma J, Bryan L, Jemal A. Breast cancer statistics, 2013. CA Cancer J Clin. 2014; 64:52-62. https:// doi.org/10.3322/caac. 21203 .

2. Hanahan D, Weinberg RA. Hallmarks of cancer: the next generation. Cell. 2011; 144:646-74. https://doi. org/10.1016/j.cell.2011.02.013.

3. Pucci-Minafra I, Cancemi P, Marabeti MR, Albanese NN, Di Cara G, Taormina P, Marrazzo A. Proteomic profiling of 13 paired ductal infiltrating breast carcinomas and non-tumoral adjacent counterparts. Proteomics Clin Appl. 2007; 1:118-29. https://doi.org/10.1002/prca.200600334.

4. Pucci-Minafra I, Fontana S, Cancemi P, Basirico L, Caricato S, Minafra S. A contribution to breast cancer cell proteomics: detection of new sequences. Proteomics. 2002; 2:919-27. https://doi.org/10.1002/16159861(200207)2:7<919::AID-PROT919>3.0.CO;2-P.

5. Pucci-Minafra I, Cancemi P, Fontana S, Minafra L, Feo S, Becchi M, Freyria AM, Minafra S. Expanding the protein catalogue in the proteome reference map of human breast cancer cells. Proteomics. 2006; 6:2609-25. https://doi. org/10.1002/pmic.200500627.

6. Pucci-Minafra I, Cancemi P, Albanese NN, Di Cara G, Marabeti MR, Marrazzo A, Minafra S. New protein clustering of breast cancer tissue proteomics using actin content as a cellularity indicator. J Proteome Res. 2008; 7:1412-8. https://doi.org/10.1021/pr700748m.

7. Cancemi P, Albanese NN, DiCara G, Marabeti MR, Costantini F, Minafra S, Pucci-Minafra I. Multiple changes induced by fibroblasts on breast cancer cells. Connect Tissue Res. 2010; 51:88-104. https://doi. org/10.3109/03008200903100651.

8. Pucci-Minafra I, Di Cara G, Musso R, Cancemi P, Albanese NN, Roz E, Minafra S. Retrospective Proteomic Screening of 100 Breast Cancer Tissues. Proteomes. 2017; 5:E15. https://doi.org/10.3390/proteomes5030015.

9. Di Cara G, Marengo G, Albanese NN, Marabeti MR, Musso R, Cancemi P, Pucci-Minafra I. Proteomic profiling of Trastuzumab (Herceptin(R))-sensitive and -resistant SKBR-3 breast cancer cells. Anticancer Res. 2013; 33:489-503.

10. Donato R. S100: a multigenic family of calcium-modulated proteins of the EF-hand type with intracellular and extracellular functional roles. Int J Biochem Cell Biol. 2001; 33:637-68.

11. Shang $X$, Cheng H, Zhou R. Chromosomal mapping, differential origin and evolution of the S100 gene family. Genet Sel Evol. 2008; 40:449-64. https://doi.org/10.1051/ gse:2008013.

12. Kuberappa PH, Bagalad BS, Ananthaneni A, Kiresur MA, Srinivas GV. Certainty of S100 from Physiology to Pathology. J Clin Diagn Res. 2016; 10:ZE10-5. https://doi. org/10.7860/JCDR/2016/17949.8022.

13. Li F, Men X, Zhang W. S100 protein in breast tumor. Indian J Cancer. 2014; 51:e67-71. https://doi. org/10.4103/0019-509X.154046.

14. Bresnick AR, Weber DJ, Zimmer DB. S100 proteins in cancer. Nat Rev Cancer. 2015; 15:96-109. https://doi. org/10.1038/nrc3893.

15. McKiernan E, McDermott EW, Evoy D, Crown J, Duffy MJ. The role of S100 genes in breast cancer progression. Tumour Biol. 2011; 32:441-50. https://doi.org/10.1007/ s13277-010-0137-2.

16. Qian J, Ding F, Luo A, Liu Z, Cui Z. Overexpression of S100A14 in human serous ovarian carcinoma. Oncol Lett. 2016; 11:1113-9. https://doi.org/10.3892/ol.2015.3984. 
17. Ma G, Sun Y, Fu S. Evaluation of S100A4 mRNA in EUSFNA specimens for the assessment of chemosensitivity to gemcitabine from patients with unresectable pancreatic cancer. Int J Clin Exp Pathol. 2015; 8:13284-8.

18. Li Y, Zhang J. Expression of S100A11 is a Prognostic Factor for Disease-free Survival and Overall Survival in Patients With High-grade Serous Ovarian Cancer. Appl Immunohistochem Mol Morphol. 2017; 25:110-6. https:// doi.org/10.1097/PAI.0000000000000275.

19. Tanaka M, Ichikawa-Tomikawa N, Shishito N, Nishiura K, Miura T, Hozumi A, Chiba H, Yoshida S, Ohtake T, Sugino T. Co-expression of S100A14 and S100A16 correlates with a poor prognosis in human breast cancer and promotes cancer cell invasion. BMC Cancer. 2015; 15:53. https://doi. org/10.1186/s12885-015-1059-6

20. Cancemi P, Di Cara G, Albanese NN, Costantini F, Marabeti MR, Musso R, Riili I, Lupo C, Roz E, Pucci-Minafra I. Differential occurrence of S100A7 in breast cancer tissues: a proteomic-based investigation. Proteomics Clin Appl. 2012; 6:364-73. https://doi.org/10.1002/prca.201100072.

21. Cancemi P, Di Cara G, Albanese NN, Costantini F, Marabeti MR, Musso R, Lupo C, Roz E, Pucci-Minafra I. Largescale proteomic identification of $\mathrm{S} 100$ proteins in breast cancer tissues. BMC Cancer. 2010; 10:476. https://doi. org/10.1186/1471-2407-10-476.

22. Rhodes DR, Yu J, Shanker K, Deshpande N, Varambally R, Ghosh D, Barrette T, Pandey A, Chinnaiyan AM. ONCOMINE: a cancer microarray database and integrated data-mining platform. Neoplasia. 2004; 6:1-6.

23. Gao J, Aksoy BA, Dogrusoz U, Dresdner G, Gross B, Sumer SO, Sun Y, Jacobsen A, Sinha R, Larsson E, Cerami E, Sander C, Schultz N. Integrative analysis of complex cancer genomics and clinical profiles using the cBioPortal. Sci Signal. 2013; 6:pl1. https://oi.org/10.1126/ scisignal.2004088.

24. Lanczky A, Nagy A, Bottai G, Munkacsy G, Szabo A, Santarpia L, Gyorffy B. miRpower: a web-tool to validate survival-associated miRNAs utilizing expression data from 2178 breast cancer patients. Breast Cancer Res Treat. 2016; 160:439-46. https://doi.org/10.1007/s10549-016-4013-7.

25. Casey T, Bond J, Tighe S, Hunter T, Lintault L, Patel O, Eneman J, Crocker A, White J, Tessitore J, Stanley M, Harlow S, Weaver D, et al. Molecular signatures suggest a major role for stromal cells in development of invasive breast cancer. Breast Cancer Res Treat. 2009; 114:47-62. https://doi.org/10.1007/s10549-008-9982-8.

26. Eryilmaz U, Demirci B, Aksun S, Boyacioglu M, Akgullu C, Ilgenli TF, Yalinkilinc HS, Bilgen M. S100A1 as a Potential Diagnostic Biomarker for Assessing Cardiotoxicity and Implications for the Chemotherapy of Certain Cancers. PLoS One. 2015; 10:e0145418. https://doi.org/10.1371/ journal.pone.0145418.

27. Masuda T, Ishikawa T, Mogushi K, Okazaki S, Ishiguro M, Iida S, Mizushima H, Tanaka H, Uetake H, Sugihara K. Overexpression of the S100A2 protein as a prognostic marker for patients with stage II and III colorectal cancer. Int J Oncol. 2016; 48:975-82. https://doi.org/10.3892/ ijo.2016.3329.

28. Woo T, Okudela K, Mitsui H, Tajiri M, Rino Y, Ohashi K, Masuda M. Up-Regulation of S100A11 in Lung Adenocarcinoma - Its Potential Relationship with Cancer Progression. PLoS One. 2015; 10:e0142642. https://doi. org/10.1371/journal.pone.0142642.

29. Fei F, Qu J, Zhang M, Li Y, Zhang S. S100A4 in cancer progression and metastasis: A systematic review. Oncotarget. 2017; 8:73219-39. https://doi.org/10.18632/ oncotarget.18016.

30. Wang XH, Du H, Li L, Shao DF, Zhong XY, Hu Y, Liu YQ, Xing XF, Cheng XJ, Guo T, Li S, Li ZY, Bu ZD, et al. Increased expression of S100A6 promotes cell proliferation in gastric cancer cells. Oncol Lett. 2017; 13:222-30. https:// doi.org/10.3892/ol.2016.5419.

31. Jia J, Duan Q, Guo J, Zheng Y. Psoriasin, a multifunctional player in different diseases. Curr Protein Pept Sci. 2014; $15: 836-42$.

32. Moris D, Spartalis E, Angelou A, Margonis GA, Papalambros A, Petrou A, Athanasiou A, Schizas D, Dimitroulis D, Felekouras E. The value of calprotectin S100A8/A9 complex as a biomarker in colorectal cancer: A systematic review. J BUON. 2016; 21:859-66.

33. Madureira PA, O'Connell PA, Surette AP, Miller VA, Waisman DM. The biochemistry and regulation of S100A10: a multifunctional plasminogen receptor involved in oncogenesis. J Biomed Biotechnol. 2012; 2012:353687. https://doi.org/10.1155/2012/353687.

34. Salama I, Malone PS, Mihaimeed F, Jones JL. A review of the S100 proteins in cancer. Eur J Surg Oncol. 2008; 34:357-64. https://doi.org/10.1016/j.ejso.2007.04.009.

35. Zhang S, Wang Z, Liu W, Lei R, Shan J, Li L, Wang X. Distinct prognostic values of S100 mRNA expression in breast cancer. Sci Rep. 2017; 7:39786. https://doi. org/10.1038/srep39786.

36. Chen $\mathrm{H}, \mathrm{Xu} \mathrm{C}$, Jin Q, Liu Z. S100 protein family in human cancer. Am J Cancer Res. 2014; 4:89-115.

37. Feng $\mathrm{G}, \mathrm{Xu} \mathrm{X}$, Youssef EM, Lotan R. Diminished expression of S100A2, a putative tumor suppressor, at early stage of human lung carcinogenesis. Cancer Res. 2001; 61:7999-8004.

38. Goh JY, Feng M, Wang W, Oguz G, Yatim S, Lee PL, Bao Y, Lim TH, Wang P, Tam WL, Kodahl AR, Lyng MB, Sarma S, et al. Chromosome 1q21.3 amplification is a trackable biomarker and actionable target for breast cancer recurrence. Nat Med. 2017; 23:1319-30. https://doi. org/10.1038/nm.4405.

39. Emberley ED, Murphy LC, Watson PH. S100 proteins and their influence on pro-survival pathways in cancer. Biochem Cell Biol. 2004; 82:508-15. https://doi.org/10.1139/o04-052.

40. Zackular JP, Chazin WJ, Skaar EP. Nutritional Immunity: S100 Proteins at the Host-Pathogen Interface. J Biol 
Chem. 2015; 290:18991-8. https://doi.org/10.1074/jbc. R115.645085.

41. Sangiuliano B, Perez NM, Moreira DF, Belizario JE. Cell death-associated molecular-pattern molecules: inflammatory signaling and control. Mediators Inflamm. 2014; 2014:821043. https://doi.org/10.1155/2014/821043.

42. Peinado H, Zhang H, Matei IR, Costa-Silva B, Hoshino A, Rodrigues G, Psaila B, Kaplan RN, Bromberg JF, Kang Y, Bissell MJ, Cox TR, Giaccia AJ, et al. Pre-metastatic niches: organ-specific homes for metastases. Nat Rev Cancer. 2017; 17:302-17. https://doi.org/10.1038/nrc.2017.6.

43. Badowska-Kozakiewicz AM, Budzik MP. Immunohistochemical characteristics of basal-like breast cancer. Contemp Oncol (Pozn). 2016; 20:436-43. https:// doi.org/10.5114/wo.2016.56938.

44. Glaser R, Harder J, Lange H, Bartels J, Christophers E, Schroder JM. Antimicrobial psoriasin (S100A7) protects human skin from Escherichia coli infection. Nat Immunol. 2005; 6:57-64. https://doi.org/10.1038/ni1142.

45. Gottsch JD, Eisinger SW, Liu SH, Scott AL. Calgranulin $\mathrm{C}$ has filariacidal and filariastatic activity. Infect Immun. 1999; 67:6631-6.

46. Sohnle PG, Hunter MJ, Hahn B, Chazin WJ. Zinc-reversible antimicrobial activity of recombinant calprotectin (migration inhibitory factor-related proteins 8 and 14). J Infect Dis. 2000; 182:1272-5. https://doi.org/10.1086/315810.

47. Buchau AS, Gallo RL. Innate immunity and antimicrobial defense systems in psoriasis. Clin Dermatol. 2007; 25:61624. https://doi.org/10.1016/j.clindermatol.2007.08.016.

48. Boomershine CS, Chamberlain A, Kendall P, Afshar-Sharif AR, Huang H, Washington MK, Lawson WE, Thomas JW, Blackwell TS, Bhowmick NA. Autoimmune pancreatitis results from loss of TGFbeta signalling in S100A4positive dendritic cells. Gut. 2009; 58:1267-74. https://doi. org/10.1136/gut.2008.170779.

49. Andres Cerezo L, Sumova B, Prajzlerova K, Veigl D, Damgaard D, Nielsen CH, Pavelka K, Vencovsky J, Senolt L. Calgizzarin (S100A11): a novel inflammatory mediator associated with disease activity of rheumatoid arthritis. Arthritis Res Ther. 2017; 19:79. https://doi.org/10.1186/ s13075-017-1288-y.

50. Chen YS, Yan W, Geczy CL, Brown MA, Thomas R. Serum levels of soluble receptor for advanced glycation end products and of S100 proteins are associated with inflammatory, autoantibody, and classical risk markers of joint and vascular damage in rheumatoid arthritis. Arthritis Res Ther. 2009; 11:R39. https://doi.org/10.1186/ar2645.

51. Yu J, Lu Y, Li Y, Xiao L, Xing Y, Li Y, Wu L. Role of S100A1 in hypoxia-induced inflammatory response in cardiomyocytes via TLR4/ROS/NF-kappaB pathway. J Pharm Pharmacol. 2015; 67:1240-50. https://doi. org/10.1111/jphp.12415.

52. Boschetti G, Garnero P, Moussata D, Cuerq C, Preaudat C, Duclaux-Loras R, Mialon A, Drai J, Flourie B, Nancey S. Accuracies of serum and fecal S100 proteins (calprotectin and calgranulin C) to predict the response to TNF antagonists in patients with Crohn's disease. Inflamm Bowel Dis. 2015; 21:331-6. https://doi.org/10.1097/ MIB.0000000000000273.

53. Batycka-Baran A, Hattinger E, Zwicker S, Summer B, Zack Howard OM, Thomas P, Szepietowski JC, Ruzicka T, Prinz JC, Wolf R. Leukocyte-derived koebnerisin (S100A15) and psoriasin (S100A7) are systemic mediators of inflammation in psoriasis. J Dermatol Sci. 2015; 79:214-21. https://doi. org/10.1016/j.jdermsci.2015.05.007.

54. Tyden H, Lood C, Gullstrand B, Jonsen A, Ivars F, Leanderson $\mathrm{T}$, Bengtsson AA. Pro-inflammatory S100 proteins are associated with glomerulonephritis and anti-dsDNA antibodies in systemic lupus erythematosus. Lupus. 2017; 26:139-149. https://doi. org/10.1177/0961203316655208.

55. Ringner M, Fredlund E, Hakkinen J, Borg A, Staaf J. GOBO: gene expression-based outcome for breast cancer online. PLoS One. 2011; 6:e17911. https://doi.org/10.1371/ journal.pone.0017911.

56. Cerami E, Gao J, Dogrusoz U, Gross BE, Sumer SO, Aksoy BA, Jacobsen A, Byrne CJ, Heuer ML, Larsson E, Antipin Y, Reva B, Goldberg AP, et al. The cBio cancer genomics portal: an open platform for exploring multidimensional cancer genomics data. Cancer Discov. 2012; 2:401-4. https://doi.org/10.1158/2159-8290.CD-12-0095.

57. Szklarczyk D, Franceschini A, Wyder S, Forslund K, Heller D, Huerta-Cepas J, Simonovic M, Roth A, Santos A, Tsafou KP, Kuhn M, Bork P, Jensen LJ, et al. STRING v10: protein-protein interaction networks, integrated over the tree of life. Nucleic Acids Res. 2015; 43:D447-52. https:// doi.org/10.1093/nar/gku1003.

58. Buttacavoli M, Albanese NN, Di Cara G, Alduina R, Faleri C, Gallo M, Pizzolanti G, Gallo G, Feo S, Baldi F, Cancemi P. Anticancer activity of biogenerated silver nanoparticles: an integrated proteomic investigation. Oncotarget. 2018; 9:9685-705. https://doi.org/10.18632/oncotarget.23859.

59. Pucci-Minafra I, Albanese NN, Di Cara G, Minafra L, Marabeti MR, Cancemi P. Breast cancer cells exhibit selective modulation induced by different collagen substrates. Connect Tissue Res. 2008; 49:252-6. https://doi. org/10.1080/03008200802147779.

60. Coppola A, Tomasello L, Pizzolanti G, Pucci-Minafra I, Albanese N, Di Cara G, Cancemi P, Pitrone M, Bommarito A, Carissimi E, Zito G, Criscimanna A, Galluzzo A, et al. In vitro phenotypic, genomic and proteomic characterization of a cytokine-resistant murine beta-TC3 cell line. PLoS One. 2012; 7:e32109. https://doi.org/10.1371/journal. pone.0032109.

61. Musso R, Di Cara G, Albanese NN, Marabeti MR, Cancemi P, Martini D, Orsini E, Giordano C, PucciMinafra I. Differential proteomic and phenotypic behaviour of papillary and anaplastic thyroid cell lines. J Proteomics. 2013; 90:115-25. https://doi.org/10.1016/j. jprot.2013.01.023. 